\title{
Darwin Cortés, Juan Gallego and Darío Maldonado* On the Design of Educational Conditional Cash Transfer Programs and Their Impact on Non-Education Outcomes: The Case of Teenage Pregnancy
}

DOI 10.1515/bejeap-2014-0162

Published online October 30, 2015

Abstract: Using a simple model to characterize adolescents' behavior, we show that the effect of educational Conditional Cash Transfer (CCT) programs on teenage pregnancy depends on the limits and conditions of the programs. The model shows that when benefits are conditional on school success or when the program has a binding duration limit, the CCT reduces teenage pregnancy rates. Using original data, we estimate this relation for two different CCT programs implemented in Bogotá, Colombia. The two programs differ in that only one of them conditions benefit renewal on school success. The empirical results are consistent with the predictions of the model. Only the program that conditions renewal of the transfer, reduces average teenage pregnancy rates. We also find that, also consistent with our model, the other program reduces teenage pregnancy rates only for those girls for which the duration limit is binding.

Keywords: teenage risk-taking behavior, teenage pregnancy, education, conditional cash transfers, incentives

JEL codes: I28, I38, J13

\section{Introduction}

Conditional cash transfer programs (CCTs) have been implemented in many countries around the world. Many of these CCTs have concentrated in increasing school enrollment and have shown to be useful for this purpose (see for example De Janvry et al. 2006 and Schultz 2004). However, other outcomes that can influence the future of youths can be affected by this type of programs.

\footnotetext{
*Corresponding author: Darío Maldonado, School of Government, Universidad de los Andes, Bogotá, Cra. 1 No. 19-27, Bloque Au, Piso 3, Bogotá, Colombia, E-mail: dmaldonadoc@uniandes.edu.co Darwin Cortés, Juan Gallego, Department of Economics and CeiBA-Complejidad, Universidad del Rosario, Bogotá
} 
The purpose of this paper is to study the effect of CCT programs on one of these outcomes, namely, teenage pregnancy. For this study we use data for adolescents from Bogotá, Colombia. ${ }^{1}$ Although the debate regarding the long-term consequences of teenage pregnancy is still ongoing, for the case of Colombia the best available evidence shows that delaying the birth of the first child implied higher investments in human capital (Miller 2010) and that teen pregnancy is associated to low-quality jobs and other low quality of life outcomes for the mothers (Urdinola and Ospino 2015). ${ }^{2}$

For the purpose of this paper, we analyze the effect of two large-scale educational CCTs - implemented in Bogotá - on teenage pregnancy. The two programs differ in their design; consequently, if their effects on teenage pregnancy also differ, the exercise may shed light on how the programs' design relates to this outcome. We use data from the ECSAE survey, ${ }^{3}$ an original data set gathering information on sexual behavior and socioeconomic conditions of urban schooled teenagers in Bogotá. The survey also allows the identification of beneficiaries and non-beneficiaries of the two education CCTs.

The two programs we analyze are Familias en Acción (FA) and Subsidio Educativo (SE). Both programs target poor households, use the same metric to determine eligibility and are similar with respect to size of the subsidy, management and verification conditions. In both cases, school attendance is a requirement to receive the subsidy. The two programs also differ in meaningful ways. More specifically, students receiving a subsidy under the SE program must complete the school year and enroll in the following in order to continue receiving the subsidy. Additionally, the subsidy cannot be recuperated after an interruption in the program. In the case of $F A$, attending school is enough to receive the subsidy regardless of academic achievement; moreover, if for some reason, a student stops attending school she will stop receiving the subsidy but she will be able to recover it once she returns.

The effects of these CCT programs on school enrollment have been studied by Attanasio et al. (2010) and by Barrera et al. (2011). Attanasio et al. show that

1 The main trends in teenage pregnancy in Latin America are summarized in Flórez and Núñez (2001) and Flórez and Soto (2008).

2 The effects of pregnancy and childbearing are studied by Angrist and Ewans (1996), Ashcraft, Fernández-Val, and Lang (2013), Brien, Loya, and Pepper (2002), Chevalier and Viitanen (2003), Fletcher and Wolfe (2009), Fletcher (2012), Geronimus (1993), Geronimus and Korenman (1992), Hoffman, Michael Foster, and Furstenberg (1993), Holmlund (2005), Levine and Painter (2003), Hotz, McElroy, and Sanders (2005) and Hotz, Mullin and Sanders (1997). There is also a literature about teen marriage, see v.g. Dahl (2010) and Field and Ambrous (2008).

3 ECSAE stands for Encuesta sobre el comportamiento sexual de adolescentes escolarizados en Bogotá (Survey About Sexual Behavior of Schooled Adolescents in Bogotá). 
FA has been effective, but the evaluation only considers rural Colombia which experiences very different conditions than big cities. Barrera et al. evaluated the pilot of $S E$. The results show that this program can be effective in increasing school enrollment and that the way the program is designed also affects the size of the effect. Baez and Camacho (2011) studied the long-term effects of $F A$ on school achievement finding no effects of the program.

Even if these programs have positive effects on school attendance, it is not obvious that they will also have the same influence on non-educational outcomes. Moreover, the effects of the programs on risky behaviors may differ in sign or size. To understand the possible effects of the programs on teen pregnancy, we use a simple model that characterizes adolescents' pregnancy rates. According to our model, an educational CCT that only conditions on school attendance has an ambiguous effect on teenage pregnancy: it may reduce or increase teenage pregnancy rates. However, conditioning program renewal on school success or limiting the number of years in which the benefits of the program can be claimed resolves the ambiguity and implies that the CCT will reduce teenage pregnancy rates.

Three predictions can be obtained from the characteristics of the two programs and the implications of the theoretical model. First, $S E$ will reduce teenage pregnancy rates. Second, the sign of the effect of $F A$ on teenage pregnancy rates will depend on particular characteristics of the program. Most notably, it will reduce teenage pregnancy when the condition on the duration of the program is binding (i.e. when girls have not finished high school before turning 18 years old). Third, if $F A$ reduces teenage pregnancy rates, its effect will be smaller than the effect of $S E$.

We use our database to estimate the effects of both programs on teenage pregnancy and to compare them with the previous predictions. For this purpose we use a difference-in-differences methods to identify the effect of the two programs, exploiting information about the interviewed girls and their siblings. We define cohorts to introduce the time dimension: the interviewed girls belong to the young cohort (after treatment) and their older sisters that attended the same school belong to the old cohort (before treatment). Similarly to Duflo (2001), the identification strategy relies on intensity differences across schools in the implementation of the CCTs to define the treatment and the control group (high-intensity and low-intensity schools).

Our empirical results are in line with the predictions of the model: on average, $S E$ reduces teenage pregnancy rates while $F A$ has no average effect on pregnancy rates. The comparison of the two cohorts allows us to show that the rate of school girls who are pregnant or already mothers and attended highintensity $S E$ schools is reduced by two percentage points with respect to those 
attending low-intensity $S E$ schools. For the case of $F A$, there is no difference between high-intensity and low-intensity $F A$ schools. When the effect of both programs is disaggregated according to age and grade, $S E$ continues to reduce pregnancy rates for some of the groups considered (without increasing it for any other group), but $F A$ may reduce or increase pregnancy rates for particular groups. Given that both programs are quite similar and that in our regressions we control for socioeconomic background, we can interpret these results as saying that incentives are crucial if one wants educational CCTs to reduce teenage pregnancy rates. These results are in line with those of Barrera et al. (2011) in that we show that there are several margins that should be considered in order to improve the efficacy of CCTs. They concentrate on the educational outcomes (attendance and enrollment) of CCTs, while our results concern noneducational outcomes.

The literature has raised some concerns about the use of information from siblings for proper identification. In particular, this approach may lead to biased estimates when there is no control for heterogeneity within the family. Holmlund (2005) has pointed out this argument for the impact of teenage childbearing on labor market outcomes. To address this concern, first, we control for heterogeneity within the family by introducing individual age, school and neighborhood variables that vary across siblings. ${ }^{4}$ Second, we also do robustness checks for our results restricting our estimates to specific sub-samples of our data.

Recently a series of studies have investigated the effect of human capital policies on teenage pregnancy: Alzua, Rodríguez, and Villa (2015) using data from 22 countries from Latin America and the Caribbean; Baird et al. (2010) and Baird, McIntosh, and Özler (2011) using data from Malawi; Bethelon and Kruger (2011) using data from Chile; Black, Devereux, and Salvanes (2008) and Silles (2011) using data from the United States; Duflo et al. (2006) using data from Kenya. All show cases in which policies that aimed to increase school attendance have also reduced teenage pregnancy. ${ }^{5}$ The main hypothesis behind the possibility that CCTs affects teenage pregnancy relies on the idea that motherhood and school attendance are competing life projects. If this is true, any program that increases the benefits of attending school and is

\footnotetext{
4 We have a database with time varying school and school neighborhood variables. For both cohorts we match the school and neighborhood variables according to the time they are/were attending school.

5 Baird, McIntosh, and Özler (2011) show a case in which CCT are less effective than Unconditional Cash Transfer programs because the last may also reduce teenage pregnancy of girls who dropped out from school.
} 
successful may also reduce incidence of teenage pregnancy. However, teen pregnancy and school attendance are not exclusive lifetime projects and, as our theoretical results show, once one allows for a probability of completing high school after becoming a mother, this hypothesis may change. Moreover, the conditions of different programs may make continuing in school after pregnancy or motherhood easier or more difficult. As a result, programs that differ in the way they are designed may have distinct implicit incentives to early motherhood. Our empirical exercise corroborates the results of the model. The results suggest that to have a robust CCT that increases school enrollment and reduces teenage pregnancy, the program must include incentives for school success, or must introduce a binding limit on the time for collection of benefits. ${ }^{6}$

This paper is composed of seven sections. The first section is this introduction. Section 2 makes a detailed description of the education subsidies implemented in Bogotá. Section 3 presents a simple model that allows to capture the effects of the two programs. Section 4 presents the empirical strategy that we use to identify the effect of the two CCTs considered on teenage childbearing. Section 5 presents the data and relevant descriptive statistics. Section 6 presents results and robustness checks. Section 7 concludes.

\section{Education Conditional Cash Transfer Programs Implemented in Bogotá}

Two CCT programs were in place in Bogotá at the moment of the data collection: Familias en Acción (FA) and Subsidio Educativo (SE). FA is the national poverty alleviation program targeting poor families, whereas $S E$ is a city government education program that aims to improve school attendance for poor adolescents in the city. This section explains details about each of the programs. Although we provide some background of the programs, we focus on the situation in 2010 and on the benefits for students in grades 9th, 10th and 11th since those are the relevant characteristics of the programs for our empirical analysis. Table 1 shows some additional characteristics of the programs.

\footnotetext{
6 Our paper is also related to the literature on the effect of economic incentives on teenage pregnancy, on this see Wolfe, Wilson, and Haveman (2001) and Lundberg and Plotnick (1995). Additionally, there is literature about related outcomes like the effect of CCT on marriage. On this see Behrman, Parker, and Todd (2009) and IEG (2011).
} 
Subsidio Educativo was introduced in 2006 targeting poor adolescents. ${ }^{7}$ The program had a first phase between 2006 and 2008, and a second starting in 2009. In 2006 and 2007 the program attended 45,000 beneficiaries of SISBEN Levels 1 and 2, randomly chosen from 136,000 applicants, aged 18 years or less and enrolled in the public secondary education (6th to 11th grades). ${ }^{8}$ The second phase starts in 2009 with a completely new cohort of beneficiaries targeting individuals in SISBEN Level 2. In 2010 the program targeted students in all grades in secondary education; it gave $\$ 25,000^{9}$ Colombian pesos to students in grades 6 th through 8 th and gave $\$ 35,000^{10}$ Colombian pesos to those in grades 9th to 11th (which correspond to the last three grades of secondary education). Payments are done each two months during the 10 months of the school year. Beneficiaries of the program lose the transfer if they do not comply with a minimum daily attendance requirement. Beneficiaries can receive the transfer for at most 2 years; renewal for the second year depends on successful promotion (and enrollment) to the following school year. SE has a variant in which a subsidy to cover transportation costs is granted to students. The amount of money that students receive and all the conditions that must be met in order not to lose the subsidy are the same as with the main variant. In addition to the eligibility requirements of the main variant, the beneficiaries of the transportation $S E$ must live more than $2 \mathrm{~km}$ away from their school.

Familias en Acción is the main Colombian CCT. ${ }^{11}$ It started in 2002 in rural areas and small cities and was extended to big cities in 2008, except for Bogotá where it only entered in 2009. In Bogotá $F A$ targets households that belong to the poorest population (SISBEN Level 1). The program gives a school attendance subsidy to families with children between 12 and 18 years. ${ }^{12}$ When our data collection process

7 Barrera et al. (2011) studied a randomized assignment pilot of SE implemented in 2005. As a result of the positive evaluation of Barrera et al. (2011) the program was extended. The pilot implemented three different versions of the program all with positive effects but of different sizes; the implemented version was not that with the most sizable effect.

8 The SISBEN welfare index is constructed using health, education, dwelling characteristics and vulnerability information. The index is used to sort households into five levels; households in Levels 1 and 2 are the poorest, with those in Level 1 being poorer than those in Level 2.

9 Equivalent to US $\$ 12.9$ with the February 2010 exchange rate.

10 Equivalent to US $\$ 18$ with the February 2010 exchange rate.

11 Although the program has the same name in the city and the country and depends from the same government agency, there are several differences in the way $F A$ has been implemented in Bogotá and in the rest of the country. Here we focus on the Bogotá case. This explains several differences between our description of the program and those of Attanasio et al. (2010) or Baez and Camacho (2011).

12 FA also gives a nutrition subsidy but this is targeted to younger children. It is important to note that when a household already makes part of the program the appearance of new children 
was developed - in 2010 - the education component of the program gave each household a monthly payment per child from 6th to 11th grade. The payment amounted to $\$ 35,000$ Colombian pesos for those attending 9th and 10th grades and $\$ 40,000$ Colombian pesos for those attending 11 th grade. ${ }^{13}$ The education subsidy is conditional on satisfaction of the minimum daily school attendance by the adolescent; if this condition is satisfied the household will receive the subsidy until the child ends highschool or drops out. If the attendance condition is not satisfied, the family loses the subsidy for the current bimester, but can regain the benefit in the following. Finally, $F A$ gives students a lump-sum of $\$ 430,000$ Colombian pesos when they successfully finish high school. ${ }^{14}$

The programs have some similarities that facilitate their comparative analysis; in this respect five points must be mentioned. First, both programs are exclusive so that a family cannot receive them simultaneously. This is easily enforced because the city government is in charge of the management of both programs. Second, the programs are not universal (even for their target populations) and target the poor population. Third, both programs use the SISBEN household welfare index for their assignment. Fourth, even if FA targets SISBEN Level 1 and SE targets SISBEN Level 2 households, the socioeconomic characteristics of both populations are very similar - both groups belong to the poorest population in the city - allowing us to construct comparable groups. ${ }^{15}$ Finally, although the history of both programs is different, since 2009 both programs started with completely new beneficiaries in Bogotá. This is important because any beneficiary of either program has been under the program for the same time.

Table 1 describes the main differences between the two programs that must be highlighted in this case in which we are concerned with the behavior of students attending the last grades of secondary education. First, even if both have a minimum daily school attendance requirement, the consequences of not complying are different for both programs. In the case of $S E$, if this minimum is not attained the student definitely loses the subsidy; in the case of $F A$ she only loses it for the current year but she can reclaim it in the following year. Second, only $S E$ conditions renewal on being promoted to the next academic grade; in the case of $F A$, students receive the transfer as long as they attend school regardless on successful progression in school.

is not used to recompute the transfer the household receives. Consequently, if individuals understand the program, the nutrition component should not be an incentive to fertility.

13 With the exchange rate of February 2010, these are equivalent to US $\$ 18$ and US $\$ 20.6$ respectively. 14 The transfer is equivalent to US\$221 with the February 2010 exchange rate.

15 This will be corroborated by our empirical analysis where we use the main variables used for the focalization of both programs. 


\section{A Simple Model to Capture the Effect of Educational Conditional Cash Transfer Programs on Teenage Pregnancy}

A priori, many forces may affect risky sexual behavior of teenagers. Among them, when analyzing the effect of CCT programs on teen pregnancy, two are key: first, the tradeoff between the labor market opportunity cost and the utility of motherhood and, second, the way different forms of CCT programs may affect this tradeoff. The purpose of this paper is to empirically assess the effect of CCT programs on teen pregnancy; however, a simple model will prove to be useful to understand the tradeoffs implied by the programs and our empirical results. Building this model is the purpose of this section. ${ }^{16}$

Consider a population of mass one of girls who are attending grade $g$ (in high school). Time is discrete and is represented by $t \in\{1, \ldots, T\}$. Each girl's life spans $T$ period, all girls discount the future with a common factor $\beta$ but they differ in age, $a$, and in their desire to become mothers, $m .{ }^{17}$ We assume that $m \in[\underline{m}, \bar{m}]$, $a \in[\underline{a}, \bar{a}]$ with $\underline{a}>0, \underline{m}>0, \bar{a}>\underline{a}$ and $\bar{m}>\underline{m}$ and let $f(a, m)$ represent the distribution function of girls of type $(a, m)$. Since all girls are in the same grade, they all have to complete the same number of additional years, $s$, before finishing high school. ${ }^{18}$ To introduce a labor market opportunity cost of pregnancy we will suppose that, if pregnant before ending high school, girls face a probability, $p \in(0,1)$, of finishing high school, but they will have to spend additional time at school, $\sigma$, before graduation (this includes years repeated or time spent outside of school).

In this stage we introduce CCT programs in a very general way. Later, we will study specific forms of this general CCT program. For this purpose assume that, during high school girls receive a transfer of size $e_{t}$ in period $t$ conditional on attending school; let $\hat{e}$ represent the vector containing all the values of $e_{t}$. Girls who do not finish high school receive a per year wage $w$; those that do finish high school receive a per year wage $w+\delta$. For simplicity and realism we will only consider CCT programs where $w>e_{t}$ for any $t$. This assumption allows

16 We are putting aside other potentially important explanations for teen motherhood, like social or behavioral effects or the correlation between sex behavior and other risky behaviors like alcohol or drug consumption.

$17 \mathrm{~m}$ represents the per year money equivalent utility of being a mother

18 Our model, recognizes heterogeneity in preferences for motherhood but assumes that all girls will eventually want to become mothers. Even if this is a disputable assumption, introducing girls that do not want to be mothers will not change the results of the model. 
us to focus on how the design of the CCT program affects the tradeoff between utility of motherhood and its labor market opportunity cost.

Motherhood implies no other opportunity costs for girls besides those related to the risk of not finishing high school or the increase in the time needed to finish. Accordingly, since all girls have a strictly positive desire for motherhood, all girls that finish high school and are not already mothers will become mothers immediately after finishing high school. At age $a$, the continuation lifetime utility of a girl that finishes high school before becoming a mother will be

$$
u^{a, m}=\sum_{t=a+s+1}^{T} \beta^{t-a}(w+\delta)+\sum_{t=a}^{a+s} \beta^{t-a} e_{t}+\sum_{t=a+s+1}^{T} \beta^{t-a} m .
$$

The life time utility of a girl that becomes pregnant during high school at period $\tau$, after $a$, is

$$
\begin{aligned}
v^{a, m}(\tau)= & p\left[\sum_{t=a+s+\sigma+1}^{T} \beta^{t-a}(w+\delta)+\sum_{t=a}^{a+s+\sigma} \beta^{t-a} e_{t} \cdot\right] \\
& +(1-p)\left[\sum_{t=a+\tau+1}^{T} \beta^{t-a} w+\sum_{t=a}^{a+\tau} \beta^{t-a} e_{t}\right] \\
& +\sum_{t=a+\tau+1}^{T} \beta^{t-a} m .
\end{aligned}
$$

Since we are assuming that the per year subsidy is always smaller than the per year wage for workers without a high school degree, when a girl decides to become a mother before graduation she will do so at age $a .{ }^{19}$ Consequently, $\tau=0$ and we can write the lifetime utility of becoming pregnant before high school graduation as follows:

$$
\begin{aligned}
v^{a, m}= & p\left[\sum_{t=a+s+\sigma+1}^{T} \beta^{t-a}(w+\delta)+\sum_{t=a}^{a+s+\sigma} \beta^{t-a} e_{t} \cdot\right] \\
& +(1-p)\left[\sum_{t=a+1}^{T} \beta^{t-a} w\right]+\sum_{t=a+1}^{T} \beta^{t-a} m .
\end{aligned}
$$

19 Otherwise, some girls may postpone motherhood only because the per period economic benefits of staying at school are higher than the labor market wage. As explained above, this is important for our results because it allows us to focus on the effect of the design of the CCT program putting aside the effect of the size of the transfer. 
All girls face a tradeoff between future labor market income, utility of motherhood and the length of time in which they receive the transfer. Depending on the preferences for motherhood, different girls will take different decisions regarding whether waiting until graduation to become mothers or not waiting and, when not waiting, how soon thereafter to become a mother. Monotonicity properties of $v^{a, m}$ allow to prove that for any age $a$ there will be a girl that will be indifferent between becoming a mother before finishing high school and waiting; this marginal girl is defined by

$$
v^{a, m}=u^{a, m}
$$

We denote the type of the marginal girl by $\tilde{m}(a, \hat{e})$. This marginal girl allows us to write the rate of girls with age $a$ attending grade $g$ that will become pregnant before finishing high school as follows

$$
r_{g}^{a}(\hat{e}) \equiv \int_{\tilde{m}(a, \hat{e})}^{\bar{m}} f(a, m) d m .
$$

Consequently, the rate of girls attending grade $g$ that will become pregnant before finishing high school is given by

$$
r_{g}(\hat{e}) \equiv \int_{\underline{a}}^{\bar{a}} \int_{\tilde{m}(a, \hat{e})}^{\bar{m}} f(a, m) d m d a .
$$

Any policy that increases $\tilde{m}$ will reduce $r_{g}$ and $r_{g}^{a}$. To show how alternative ways of designing the CCTs affect teenage pregnancy we consider particular cases chosen to match the main characteristics of the two Colombian CCTs we analyze in this paper. These are characteristics that could be considered to be included in any other CCT program in the world.

\section{Case i. The effect of an educational CCT that only conditions on school} attendance: In addition to the assumptions above, suppose also $\beta=1$ and $e_{t}=e$. Note that we are assuming that a girl that becomes pregnant and receives the subsidy, if she is able to finish high school, will continue receiving the subsidy until she graduates. This means that pregnancy does not make girls leave school temporarily and that $\sigma$ only represents the time cost of repeating a year. Under these assumptions we have that

$$
u^{a, m}=(T-a-s-1)(w+\delta)+s e+(T-a-s-1) m
$$


and

$$
\begin{aligned}
& v^{a, m}=p[(T-a-s-\sigma-1)(w+\delta)+(s+\sigma) e] \\
& +(1-p)(T-a-1) w+(T-a-1) m .
\end{aligned}
$$

Using the above equations for $u^{a, m}$ and $v^{a, m}$, eq. [1] implies that

$$
s \tilde{m}^{i}(a, e)=[(1-p)(T-a-s-1)+p \sigma] \delta-[s-p(s+\sigma)](w-e) .
$$

Since $\tilde{m}^{i}$ decreases with $a$, for a given $m$, older girls will become pregnant more frequently. Let $r_{g}^{a, i}$ represent the rate of girls that become pregnant under this type of program; as before $r_{g}^{a, i}$ is a function of $e$.

From eq. [5]

$$
\frac{\partial}{\partial e} \widetilde{m}^{i}(a, e)=[s-p(s+\sigma)] / s
$$

which can be positive or negative. It will positive, and consequently the CCT will reduce teen pregnancy, if

$$
\frac{s}{s+\sigma}>p
$$

To understand this result, note that if there is no cost of pregnancy in terms of additional time needed to graduate, $\sigma=0$, the CCT will reduce teen pregnancy (since $p<1$ ). Similarly, if $p=0$, the CCT program will always reduce teen pregnancy (provided $s>0$ ). More generally the CCT will reduce teenage pregnancy if the probability of finishing high school is low or if $\sigma$ is low. In both cases the penalty for teenage pregnancy is significant. When $p$ is low girls perceive high opportunity costs of pregnancy; when $\sigma$ is low girls perceive low collateral economic benefits or prolonged time at school since they will receive the subsidy for a short additional period. This last result may be puzzling. However, it can be understood noticing that pregnancy can be a way to prolong the period in which any girl benefits from the CCT. ${ }^{20}$

This case shows that an educational CCTs does not necessarily reduce teenage pregnancy. We will now show that CCTs can be designed (in theory) to unambiguously reduce teenage pregnancy; to achieve this the CCT must either be conditioned on school success or must limit the number of years in which the student is a beneficiary of the program.

20 Note also that we are not saying that increasing the opportunity cost of motherhood (increasing $\sigma$ ) will increase teen pregnancy rates; of course this will not be the case. We are only pointing to an interaction between the existence of the CCT program and the possibility that teen pregnancy extends the time until high school graduation. 
Case ii. The effect of limiting the number of years under the CCT program: Now suppose that, additional to the conditions in the general setting, $\beta=1$ and that $e_{t}=e>0$ for $a \leq t \leq a+s$ and $e_{t}=0$ for $t>a+s$. With this assumptions we are assuming that the time in which a girl receives the subsidy is fixed, equal to the time needed to finish high school if she does not become pregnant but shorter if she becomes pregnant. In this case we have that the expression for $u^{a, m}$ is given by eq. [4] and that

$$
\begin{aligned}
v^{a, m}= & p[(T-a-s-\sigma-1)(w+\delta)+s e] \\
& +(1-p)(T-a-1) w+(T-a-1) m .
\end{aligned}
$$

The marginal girl that will be indifferent between waiting or becoming pregnant at age $a$ is defined by

$$
s \widetilde{m}^{i i}(a, e)=[(1-p)(T-a-s-1)+p \sigma] \delta-(s-p s)(w-e)+p \sigma w .
$$

In this case

$$
\frac{\partial}{\partial e} \tilde{m}^{i i}(a, e)=1-p>0
$$

Accordingly, introducing a binding limit to the number of years in which the CCT can be claimed, unambiguously leads to lower pregnancy rates. The ambiguous effect of the CCT on teen pregnancy in Case i above does not impede ranking teen pregnancy rates in Cases $i$ and ii, since

$$
\tilde{m}^{i}(a, e)-\tilde{m}^{i i}(a, e)=-p \sigma e / s<0 .
$$

Consequently, $\tilde{m}^{i i}>\tilde{m}^{i}$. Let $r_{g}^{a, i i}$ represent the rate of girls that become pregnant under this type of program; as before $r_{g}^{a, i i}$ is a function of $e$.

Case iii. The effect of conditioning renewal on performance: Suppose now that girls stop receiving the transfer if they fail to successfully finish the academic year and that $e_{t}=e>0$ for all years in which the girls receive the subsidy. As in Case ii, the lifetime utility of waiting until graduation to become a mother is represented by eq. [4], but the lifetime utility of not waiting is represented by

$$
\begin{aligned}
v^{a, m}= & p(T-a-s-\sigma-1)(w+\delta) \\
& +(1-p)(T-a-1) w+(T-a-1) m .
\end{aligned}
$$

In this case the marginal girl is defined by

$$
s \widetilde{m}^{i i i}(a, e)=[(1-p)(T-a-s-1)+p \sigma] \delta-[(s-p s) w-s e]+p \sigma w
$$


and we have that

$$
\frac{\partial}{\partial e} \widetilde{m}^{i i i}(a, e)=1>0
$$

This means that introducing a subsidy with the stated rules reduces teen pregnancy.

Moreover

$$
\widetilde{m}^{i i i}(a, e)-\widetilde{m}^{i i}(a, e)=p e>0
$$

so that conditioning the renewal of the subsidy on school success reduces teenage pregnancy rates compared to both cases in which this condition was not used. Similar to the previous two cases, let $r_{g}^{a, i i i}$ represent the rate of girls that become pregnant under this type of program; as before $r_{g}^{a, i i i}$ is a function of $e$.

Case iv. The effect of the timing of incentives: We need to understand the effect of delaying some benefits until the end of high school. This case needs no formalization since it is clear that, if girls discount future utility $(\beta<1)$, or exhibit any sort of myopia, any alternative to the previous three cases which leaves some resources until the end of high school and keeps constant the financial costs of the program will have higher pregnancy rates than the original program. Note that in this case we are not making any implication about the effect of the program and attendance decisions as the ones analyzed by Barrera et al. (2011).

To summarize we have shown that the way in which CCT programs are designed may have important effects on teen age pregnancy. In particular, those programs that condition renewal on academic performance will lead to lower pregnancy rates than those that do not condition on academic performance. Programs in which there is a limit on the number of years the benefits can be claimed reduce pregnancy rates and have lower pregnancy rates than those in which there is no limit. This means that

$$
r_{g}^{a, i i i}(e)<r_{g}^{a, i i}(e)<r_{g}^{a, i}(e)
$$

If on top of the conditions of programs described in i, ii or iii, some of the resources are given only after girls finish high school, pregnancy rates will be higher than without partially delaying resources. What explains this relation is the way in which the CCT interacts with the different elements that introduce the labor market opportunity cost of teen motherhood. 


\section{Empirical Strategy}

In Section 3 we used a simple model to show that education CCTs may affect teenage pregnancy and that the characteristics of the programs determine the exact form of this relation (sign and size). In this section we consider the empirical strategy we will use to estimate the relation.

Let the probability of becoming pregnant for a girl of age $a$, attending grade $g$ in school $j$ under a CCT with characteristics represented by $\hat{e}$ be given by

$$
\operatorname{Prob}\left[u^{a, m} \geq v^{a, m}\right] \equiv q(\hat{e}, a, j, g) .
$$

Equation [2] suggests that an empirical exercise to capture the differential effects of two education CCTs on teenage pregnancy must estimate

$$
\Delta q(\hat{e})=q(\hat{e}, a, j, g)-q(0, a, j, g) .
$$

A complete set of interventions where $\hat{e}$ varies is rarely available. Rather, one may have access to data about specific programs that differ in their conditions which translate into different forms of $\hat{e}$. This is the case in which we are since we have data about girls that may have been treated by one of two programs or by none of them. To take this into account let $t$ indicate whether the girl was treated by one of the two programs, $t \in\{F A, S E\}$. In this case the probability of becoming pregnant is given by

$$
\operatorname{Prob}\left[u^{a, m} \geq v^{a, m}\right] \equiv q(t, a, j, g)
$$

To identify the effect of each of the two programs we can then estimate the equation

$$
\Delta q(t)=q(t, a, j, g)-q(0, a, j, g)
$$

Since the programs are similar enough in most characteristics, we can attribute the difference in the estimates to differences in the form in which they are designed.

According to eq. [9] we can expect to find a lower pregnancy rate under a program that conditions renewal on performance than under one that does not. Moreover, our model also shows that a program that does not have a binding limit on the number of years the benefits of the program can be claimed may have a positive effect on teenage pregnancy rates. Although $F A$ includes this type of condition, in practice, the rule is not binding for many Colombian girls since many of them end high school before being 18 years old. Consequently, we expect that $\Delta q(F A)>\Delta q(S E)$; we can also expect $S E$ to reduce teenage pregnancy and for $F A$, we may expect to have positive and negative effects depending on whether the age limit is binding or not. 
The treatment variables are defined at the school level. We consider a treatment given by a dummy variable, so that we split schools in two groups: schools with high treatment and schools with low treatment. The indicator variable for treatment $t, t \in\{\mathrm{FA}, \mathrm{SE}\}$, in school $j$ is defined as follows:

$$
T_{t j} \equiv \mathrm{ll}\left[\pi_{t j}>\bar{\pi}_{t j}\right]
$$

where $\pi_{t j}$ denotes the proportion of girls in school $j$ that receive the treatment $t$ and $\bar{\pi}_{t j}$ denotes the average proportion of girls receiving treatment $t$ across schools.

Since we have cross-section data we do not have information from before and after the treatment for the same individuals. Instead, in the same vein of Duflo (2001), we define two cohorts which differ in their likelihood of having been treated. These two cohorts allow us to use a difference-in-differences strategy to identify the effects of the subsidies on teenage pregnancy. In our paper the two cohorts are constructed using information provided by the girls about the older sisters. This strategy allows us to control for unobservable variables at the household level that do not vary across time. To make both cohorts more similar we further restrict our data only including girls and their sisters when both attended the same school and when the sister finished high school. This restriction also allows to control for school characteristics that do not vary across time.

Since we have two treatments, to fully identify the effect of those treatments we estimate the following equation:

$$
\begin{aligned}
Y_{i j}= & \alpha+\alpha_{C} C_{i}+\alpha_{F A} T_{F A j}+\alpha_{S E} T_{S E j}+\alpha_{F S} T_{F A j} T_{S E j}+ \\
& \beta_{F A} T_{F A j} C_{i}+\beta_{S E} T_{S E j} C_{i}+\beta_{F S} T_{F A j} T_{S E j} C_{i}+ \\
& y^{\prime} X_{i j}+\delta^{\prime} Z_{j}+\varepsilon_{i j}
\end{aligned}
$$

where $Y_{i j}$ is a dummy variable that takes value 1 when woman $i$ who attends or attended school $j$ had at least one child during teenage (between 14 and 19 years old) and value 0 otherwise. The cohort to which woman $i$ belongs is given by $C_{i}$. $C_{i}$ takes value 1 if she is in the young cohort, i.e. girls aged 14 to 19 who are still attending school; it takes value 0 if she is in the old cohort, i.e. women aged 19 to 32 and already out from school. ${ }^{21} T_{t j}$ identifies whether school $j$ is a high intensity treatment school under program $t \in\{F A, S E\}$ according to eq. [11] above; $X_{i j}$ is a vector of individual characteristics; $Z_{j}$ is a vector of school

21 Recall that women in the young cohort correspond to the girls interviewed in our field work and women in the old cohort correspond to their older sisters. 
characteristics, including fixed effects by regions of Bogotá. ${ }^{22}$ This equation corresponds to a linear version of eq. [10]; besides linearity we also allow the possibility of additional controls to include individual and school characteristics that do not appear in the model of Section 3.

Our main coefficients of interest are $\beta_{F A}$ and $\beta_{S E}$. As already explained, the identification strategy corresponds to a difference-in-difference approach taking advantage of the existence of school with high and low intensity treatment. The effect of each treatment will be identified by the estimation of coefficients $\beta_{t}, t \in\{F A, S E\}$. The effect of the interaction of both treatments above and beyond the effect of each treatment will be identified by the estimation of coefficient $\beta_{F S}$.

Additionally, we will check whether there are heterogeneous effects across grades, ages and, grades and ages combined. We do so by including interactions in eq. [12]. Our intuition that there may be heterogeneous effects according to these two dimensions is as follows. We have explained that eligibility for both programs depends on age and grade in which girls are enrolled. This means that girls of different ages in a given grade may face differing opportunities to benefit from the program. To see this more clear consider as an example a girl that is 17 years old, attends 10th grade and will be 18 years old before finishing 10th grade. She will not be able to benefit from either of the two programs after the current year. For this girl, the program will not imply any incentive related to pregnancy; the probability of this girl to become pregnant, compared to that of a girl that is 16 years old and who will loose the subsidy in case she gets pregnant and is forced to stop her education, is higher.

As a second example that highlights the differences of implicit incentives of the two programs, consider a girl that benefits from $S E$, who attends 11th grade and will be 17 years old before re-enrolling in school in case she has to repeat the year. This girl will not be able to benefit from an additional year of the program under any circumstance; if the same girl is beneficiary of $F A$ she will be able to benefit from the subsidy for an additional year if she fails the year and decides to repeat it. The probability of becoming pregnant of the first girl will be lower than that of the second girl, since the presence of the subsidy may help the girl in the second case to become pregnant. ${ }^{23}$

22 Regions in Bogotá are called localidades.

23 Recall that in our model all girls have a positive utility of motherhood. Girls for which this is not the case will not become pregnant in any case. 
As usual, there are several challenges to credible identification using this approach. ${ }^{24}$ The key identifying assumption behind the difference-in-differences approach is that selection biases are linear and time-invariant. In other words, if there is any difference in the outcome for the pre-treatment period, the difference should be stable across time. In order to test this we run two different exercises. First, using our main data, we run a placebo regression where we only include data from the old cohort. We split the old cohort into two groups by age. Younger sisters (19-22 years old) are included in one group and older sisters (23-32 years old) in the other one. There must be no effect of treatments on teenage pregnancy across sisters in order to credibly identify the effects estimating eq. [12].

A second challenge to our approach comes from the fact that we subestimate the likelihood of teenage pregnancy of the younger cohort. The reason is that, unlike the older cohort, not all individuals in the younger cohort have finished their teenage years so the odds of us observing pregnant girls are lower for girls in the young cohort. We tackle this problem by controlling for individual age. The younger the girl the less likely teenage pregnancy. Introducing age as a covariate should correct the expected pregnancy rate for each cohort.

Another challenge to the identification of the effects comes from the definition of cohorts. On this respect there are two sources of potential bias to our results. First, since $S E$ started in 2006 and $F A$ in 2009, some women from the old cohort - between 19 and 22 years old - have some probability of having been treated by $S E$. This fact may bias our results because we would be including treated girls in the old cohort. Second, since differences between conditions of girls in the same household may increase with the age difference of the girls, inclusion of sisters who are too old may also bias our results. Acknowledging these possible biases in our exercises, we make robustness checks in which we run the same regressions, but with a restricted sample where the youngest and oldest women are not included. ${ }^{25}$ In addition, since girls in the young cohort may be linked to more than one older sister, we make

24 Camacho et al. (2011) shows evidence of possible manipulation of the SISBEN index that can potentially affect our estimates. However, the database used by Camacho et al. (2011) corresponds to the "old" version - implemented between 1994 and 2003 - of the index in which the formula for the index was publicly disclosed. Starting in 2004 there is a new formula which is not publicly disclosed; consequently manipulation of the index is not a source of concern for programs that use the index after that year. This is the case for the data we are analyzing since all individuals covered by the program in our database entered the programs when the new formula was in place.

25 To maintain control on household and school fixed effects, whenever we exclude a group of girls we also exclude their sisters. 
a robustness check in which we restrict the sample to include only the youngest old sister. This is a kind of acid test to our results because of the downward bias we explained above.

A fourth challenge to our estimates comes from our definition of treatment. Our treatment dummies are based on an ad-hoc threshold (the mean proportion of treated girls across schools) to separate high intensity and low intensity treatment schools. To test how sensible to this ad-hoc definition, we use alternative definitions of the treatment dummies based on different thresholds.

We further check whether the fact of solely including sisters in the old cohort that did not drop out from school plays a role in our results. Our initial restriction - not including sisters who dropped out - is motivated by the fact that in our data we do not observe girls in the young cohort who have dropped out from school; as explained above with this restriction we want to make both cohorts more comparable. However, it is still important to check how our estimates change when this restriction is relaxed. Consequently, as a robustness check we run the same specification of our benchmark equation including sisters in the old cohort who did not finished high school but still attended the same school as their younger sisters.

An important challenge comes from the fact that we are interested in comparing the effects of two different CCT programs using observational data. Selection of households into FA and SE is based on socioeconomic characteristics; both programs are targeted to the poor households but FA is targeted to the poorest of the poor. Consequently, we expect $F A$ households to have worse socioeconomic conditions than SE households. Under the identifying assumption, the effect of socioeconomic differences on pregnancy is swept out. However, the results continue to be conditional on the targeted population. Thus, if the identifying assumption does not hold, the difference in the estimation of the effects of the two programs can be partially explained by differences in covariates across treatments instead of treatments themselves. To check this point, we run the regression (12) on a matched sample. We perform a Mahalanobis matching based on a propensity score estimated on socioeconomic characteristics (Rosenbaum and Rubin 1985). We proceed in two steps. We first match young-cohort girls across the treatment groups, FA and SE. We then match the sample selected in the previous step with young-cohort girls in the control group. In this way we make girls across treatments more comparable to each other as well as to girls in the control group. In the regression analysis we use the old-cohort sisters of the young-cohort girls that were matched following the previous procedure. All regressions are performed clustering residuals at the region level (localidad). 
A final challenge comes from the fact that the two programs have different histories and that students remain in the programs for periods of different lengths (FA for a maximum of six years and $S E$ for a maximum of two years). However, note that our data was collected in the beginning of 2010, and that in 2009 both programs were covering entirely new beneficiaries so that in our data we will not have beneficiaries that have been in the program for more than one year.

\section{Data and Descriptive Statistics}

As explained in the introduction, the empirical analysis uses information from the ECSAE Survey. This is an original survey of boys and girls enrolled in 273 urban schools in Bogotá. ${ }^{26}$ The field work to construct this database took place between the months of February and April 2010. The survey interviewed adolescents between 14 and 18 years enrolled in the three last years of high school $^{27}$ in public and private schools. The sample has been selected with a probability proportional to population size estimated from Bogotá's 9th to 11th enrollment for the year 2009 so that the survey is representative at the regional level (localidades). For the purpose of this study, only the data from girls is relevant; the final database contains information of 24,860 girls. In this section, we discuss the information that is used to evaluate the effect of educational policies on teenage pregnancy.

For the purpose of this study, the main information in the database concerns pregnancy, fertility and the incidence of the CCTs. The survey also collected socioeconomic information and information on mother and sisters' fertility and education. To improve our information, we included administrative data from the school and neighborhood level. The school-level information includes school facilities and school level average results on the main national standardized test that high school graduates take. The neighborhood level information includes crime incidence and neighborhood safety.

In order to evaluate the impact of the CCTs implemented in Bogotá on teenage pregnancy, we take advantage of the information collected about older sisters of the interviewed girls. This information allows us to identify sisters' childbearing, age, age when the first child was born, and if the sister studied in the same school the last year attended. From the 21,262 interviewed

26 The number of schools visited amounts to roughly one fourth of all schools offering 9th, 10 th and 11th grades in the city.

27 In Colombia these correspond to 9th, 10th and 11th grades. 
girls we recovered information on childbearing, age and age at the first child for 3,598 sisters. As was stated in the empirical strategy section, we use the sister's information to build an old cohort which could be comparable with the interviewed girls, but who were less likely to be affected by any cash transfer in Bogotá. The old cohort is composed by sisters that meet all the following conditions: i. 19 to 32 years old, ii. studied in the same school as their interviewed sisters and iii. did not drop out from high school. Our final sample has 1.251 sisters (53.35\%) in the old cohort and 1,094 interviewed girls (46.65\%) in the young cohort (see Panel A and Panel B of Table 2). This table also reports frequencies of girls across treated and non-treated schools for both $F A$ and $S E$.

In the rest of this section we present some descriptive statistics on teenage pregnancy, individual characteristics, school quality and conditions of the neighborhood. In Table 3 we compare average characteristics across cohorts (Panel A) and treatment and control groups for both cash transfers (Panel B and Panel C). ${ }^{28}$ The first three columns of each of those panels provide information on the total sample including recovered information on sisters. The last three columns report information on the sub-sample used for the econometric exercise. In Panel A we report data on the interviewed girls (young cohort) and their older sisters (old cohort). In the full sample (column 1) the interviewed girls are characterized by a teenage pregnancy incidence of about 3\%, their age is around 15 years old on average, the average household has 5.26 members, their mothers have 3.24 children in average and $24 \%$ of the girls study in private schools. The household variables are measured as ordered categorical variables. While on average both parents have incomplete high school, this is not the case for FA households, where on average parents have complete primary. Regarding dwelling conditions, households are relatively similar. The other variables describe school quality (larger index means higher quality), distance to the nearest bus station and neighbor security (theft number per thousand inhabitants). ${ }^{29}$

Columns 1, 2 and 3 from Panel A of Table 3 show that girls in both cohorts, in the original database, differ in important ways in several characteristics. Columns 4, 5, and 6 show that the methodology explained in the previous section makes both cohorts more similar in most characteristics.

Comparing treated and control groups for both programs we can see that, on average, these groups are different. For both programs, girls in both cohorts from treated schools (high intensity) come from less educated and bigger

28 In Appendix B we report the definition of all variables used in the empirical exercise.

29 Our school quality index is the 5th grade math average score in the SABER examination (a general public examination carried out by the national government). 
households, study in schools with lower quality and live in regions exposed to less crime rates than girls from the control schools (low intensity). Differences in girls' age are not significant (see Panel B and Panel C of Table 3). Differences are larger for $F A$ than for $S E$, which reflect the fact that $F A$ attends the poorest households.

Table 4 shows the unconditional effects of both programs. Consider first the effect of $S E$ in the second panel. Notice that the treated schools have higher teenage pregnancy incidence than control schools before the treatment is implemented (7.4\% against 3.5\%). After the treatment, both treatment and control schools end up with similar pregnancy prevalence $(2.5 \%$ and $2.3 \%$, respectively). The teenage pregnancy incidence decreases 1.2 percentage points in the control group and 4.9 percentage points in the treatment group. Without controlling for observable covariables, the effect of $S E$ on teenage pregnancy amounts to a reduction of 3.7 percentage points. A similar analysis shows that $F A$ seems to have caused an increase in teenage pregnancy of 2.2 percentage points.

The previous result already gives an idea of the effect of both programs on teen pregnancy. Before further exploring this relation and interpreting these results as causal, there is an important issue we must address. Our database contains information of girls who were actually attending school in the moment in which we visited schools. This implies that we do not observe girls who dropped out from school, girls who dropped out and came back to school after our data collection or girls who dropped out and returned to a different school. The two programs may also be responsible for differences in decisions to permanently or temporarily drop out from school and even to returning to school after dropping out. For example, it can be hypothesized that after dropping out because of pregnancy, girls from families with the $F A$ subsidy may be more prone to return to school than girls that once had the $S E$ subsidy. It is not possible to say, a priori, which is going to be the hypothetical effect of both programs on drop out behavior related to teen pregnancy. However, the effect can be different for both programs and this may bias our results.

To address this possible selection issue, we cannot use our database, but we can study dropout rates using external data to grasp the differences in dropout rates associated with both programs in the schools in our sample. If we find that drop out rates between schools treated by the two programs are not different, we can believe that the selection problem is not an important one. This is what we show in Table 5. The table shows estimates of the effect of the two programs on school female dropout rates. The estimates are done using an administrative panel database at the school level that covers the years 2005-2010 and that has 
been restricted to the schools in our sample. ${ }^{30}$ For this exercise dropping out is defined as being present in a given school in a given year and not being present in the same school the following year. ${ }^{31}$ Consequently, three types of girls are considered as drop outs: those that have definitely dropped out of the system, those who are temporarily absent from school and those who leave the schools in our sample. The first panel of Table 5 shows a difference-in-differences estimate in which the time dummy takes a value of zero for years previous to 2009 and of one for 2009 and 2010. The second panel shows panel data estimation. Both exercises show that the effect of the two programs on drop out rates does not significantly differ from zero. This result shows that, in the schools in our sample, there does not seem to be a selection problem affecting the relation between school dropout and being treated by either of the two programs.

\section{Results and Robustness Checks}

The model in Section 3, summarized in eq. [9], predicts that an education CCT program that does not condition on performance and does not limit the number of years in which the program benefits can be claimed will cause higher pregnancy rates than alternative programs in which these two conditions are included. This is explained by the characteristics of educational CCTs that only condition on school attendance. If our model accurately predicts the relation between educational CCTs and teenage pregnancy we can expect $S E$ to have lower pregnancy rates than FA. Our model also allows to predict that the two programs will have different effects on teen pregnancy rates of girls of different ages and grades. As we will show now, our empirical results are in line with the predictions of the model. The main results are shown in Tables 6 and 7. Table 6 shows the main results where the effect of the two programs is calculated including several sets of covariates; Table 7 shows estimates of the effects of both programs for girls differing in age and grade. In summary we find that $F A$, on average, has no effect on teenage pregnancy, but increases or reduces teenage pregnancy for particular groups of girls. $S E$ on average reduces teenage pregnancy; moreover, we find that there is no group of girls (differing in age and grade) for which the program increases teenage pregnancy. All results and robustness checks appear in the Appendix.

30 This database is constructed from the students' registry handled by the Colombian Ministry of Education.

31 This also explains why we can not measure dropout rates for grade 11. 
In the first four columns of Table 6, we report estimates of eq. [12] using Ordinary Least Squares. ${ }^{32}$ In column 1 we report results with no controls except for school fixed effects and age. In the second column we introduce controls at the household, ${ }^{33}$ school $^{34}$ and locality ${ }^{35}$ level. ${ }^{36}$ First, note that the estimates of the coefficients associated with the interaction of the cohort and the programs have the same sign and are of similar size in both specifications. Second, FA has no effect on teenage pregnancy on average and $S E$ causes a reduction of teenage pregnancy. In columns 3 and 4 we report results for the same specifications in columns 1 and 2, without school fixed effects. Results are robust to these specifications. In the last two columns of Table 6 we report the marginal effects obtained from Probit estimations to have a better assessment of the size of the effect of each program. The results of the Probit estimations are consistent with those in the previous columns and show that $S E$ reduces the incidence of teenage pregnancy by around two percentage points and that $F A$ has no effect.

Our model predicts that the effect of CCTs on teen pregnancy depends on the age of each girl; the effect may also depend on the grade. Following this prediction we ran the same specification in eq. [12] adding interactions of the effect of the programs with grade and age. Table 7 shows that the effect of the programs on pregnancy varies across both dimensions. To facilitate comparisons, in the first column, we report the main results (column 2 of Table 6); columns 2, 3 and 4 report results of estimations with different sets of interactions. The results in Panel A show that $S E$ reduces pregnancy in all grades. All coefficients are negative, but only that for 10th grade is significant. The results also show that the non significant effect of $F A$ is the net effect of two opposite effects: the FA program seems to increase pregnancy among girls in 9th and 10th grade and reduce that of girls in 11th grade. Only the effect of 10th grade is significant.

32 Estimates of all coefficients are available upon request.

33 Household size, number of mother's children, parents' education, dwelling conditions (floor, waste water, toilet) and number of rooms at home.

34 Student-teacher ratio, quality, private/public and distance to public transport system.

35 Crime rates, fixed effects.

36 It would have been desirable to control for information at the neighborhood level; teenage pregnancy prevalence would have been the first candidate to be included as a control. We are not able to include these controls because the data was collected in visits to schools and there is not information from home address of the teenagers. However, our specification includes school fixed effects and since many students report living near their school (70\% report walking to school and for $95.5 \%$ of them it takes less than 30 minutes to go from home to school) we can presume that neighborhood effects are not a concern in our estimations. 
Similar results are obtained when we look at heterogeneous effects across age (see Panel B of Table 7). The SE program reduces teenage pregnancy at all ages except for girls 18 years old; however, this last effect is non significant ${ }^{37}$ while those for ages 14, 15 and 17 are significant. FA has negative or positive effects depending on age; the only two which are significant are those for 16 and 18 years, the first is positive and the second is negative.

In Tables 8 and 9 we report the robustness checks corresponding to the challenges mentioned in the empirical strategy section. ${ }^{38}$ Table 8 has three panels. In column 1 of Panels A and B we report the results showed in column 2 of Table 6 as a benchmark. In column 2 Table 8, Panel A, we report results of the placebo treatment. We split the sample of the old cohort in two: younger sisters (19-22 years old) and older sisters (23-32 years old). We must have no effect in order to validate the identifying assumption of our approach. As we can see, treatment has no effect on older cohorts, so we can credibly attribute our findings to the CCTs. In column 3 we include in the regression sisters that dropped out of school. For all the previous results our database includes all older sisters of the girls we interviewed and the interviewed girls; in column 4 we run the same regression, but we only keep the younger sister and the corresponding interviewed girl. Results are robust to all specifications.

In Table 8, Panel B, we report results of regressions in which we test whether our results are robust to the definition of cohort. In column 1 we report our benchmark regression. In column 2 we exclude the younger sisters from the old cohort. ${ }^{39}$ In column 3 we exclude the older sisters from the old cohort. In column 4 we exclude older sisters and younger interviewed girls with the aim to have girls of similar age in both cohorts. Our results hold in all regressions.

In Table 8, Panel C, we report results obtained when we change the threshold that defines the treatment variable. We show results for four different percentiles ranging from 30th percentile to 60th percentile. The effect under all thresholds is negative. It is significant for thresholds based on the range from the 30th to the 50th percentile. The effect is not significant for higher (lower) percentiles. ${ }^{40}$

37 The standard error is four times bigger than the coefficient.

38 To make the robustness checks in Table 8 clearer it is important to recall that our pregnancy definition for the old cohort only refers to pregnancy during teenage years.

39 We also exclude their sisters in the other cohort in order to maintain the siblings approach. 40 It should be clear that the risk of misclassification of a given student as being in the control (treatment) when is actually treated (control) increases for thresholds based on percentiles that are toward the upward (downward) tail of the distribution. 
Finally, in Table 9 we report the same estimations of columns 1 and 2 of Table 6 but performed over the matched sample. ${ }^{41}$ Results are very similar in magnitude and significance to those reported in Table 6. This gives evidence that our findings are not driven by differences in covariables across treatment or control groups.

The theoretical predictions of our model about the link between CCTs and teenage pregnancy can be seen from the average effects in our benchmark estimation. Our empirical findings show that $S E$ has a negative significant effect on teenage pregnancy while $F A$ has a null effect. The renewal of $S E$ is conditioned on school performance since the girl (or her family) will only receive the subsidy if she enrolls in the following grade. FA does not condition renewal on performance but limits the number of years in which the subsidy can be claimed since only families of girls younger than 18 years can claim the subsidy. However, since most girls are young enough to be able to spend one more year in school without losing the subsidy the limit is not binding. In fact, in our database, in any grade, more than half of the girls would receive during one more year the subsidy if they have to repeat a year since they will still finish high school before becoming 18 years old. The heterogeneous effects also support these findings. For none of the groups we have considered (disaggregated by age and grade) we have found a positive and significant effect of $S E$. However, for $F A$ we found positive and negative significant effects for particular groups of girls according to their age and the grade in which they are enrolled.

\section{Final Remarks}

The results in this paper suggest that not all education Conditional Cash Transfer programs (CCTs) reduce teenage pregnancy. To show this we compared the effect of two CCTs implemented in Bogotá, Colombia, i.e., Familias en Acción and Subsidio Educativo. Our main finding is that $S E$ causes a sizable reduction on teenage pregnancy while $F A$ has no effect. Unlike $F A, S E$ has a renewal condition based on performance at school and a permanent loss of CCT if the minimum daily attendance condition is not fulfilled. Conditions like these are key for policy makers when other non-educational outcomes, such as teenage pregnancy, are at stake. Our results also show that the programs will have

41 The t-test results on the bias reduction after the matching procedures show that the matched sample is balanced. These tests are reported in Tables 10 and 11. 
heterogeneous effects that will be related to the way the program is designed. This implies that, in CCT education programs, age and grade limits must be chosen so as to align the incentives that the program wants to provide with students' characteristics.

These results show that carefully designing educational CCTs is crucial in guaranteeing that non education outcomes also improve or at least that they do not worsen. Recently a discussion about the benefits of educational CCTs in the urban world has started; the benefits of these programs are challenged (compared to what happens in the rural world). Policy makers start to be concerned with dimensions different from school attendance in the urban regions of many middle income countries. Our results show that using CCTs may still be valid but they should be conditioned to other variables together with school attendance.

The results of this paper highlight important tradeoffs that must be faced in the design of CCT programs. First the fact that not all CCT programs that improve education attainment also reduce teenage pregnancy rates calls for careful revision of CCT programs in view of each society needs and constraints. Second, the effect of CCT programs on girls who drop out from school should also be considered when designing this type of programs. Our results concern the effect of CCT programs on teenage pregnancy of girls attending schools while Baird, McIntosh, and Özler (2011) show that the type of conditionality of these programs also affect girls who drop out from schools. Clearly the results of Baird, McIntosh, and Özler (2011) put together with those of this paper point to a tradeoff between pregnancy rates of girls attending schools compared to those not attending. Third, Barrera et al. (2011) show that delaying rewards until the end of high school may help increase attendance to higher education since that reduces resources constraints that may affect the capacity to pay for starting costs in higher education. However, our theory also shows that due to time discounting, delaying rewards may imply an increase in teenage pregnancy rates. Finally, it is also possible that in a world in which students face psychological costs of attending school, including performance conditions may discourage some students from attending school. These elements make part of the tradeoffs that must be solved for a good policy design.

Acknowledgment: We thank Catalina Latorre and Mónica Ortegón for their participation in the field work and the questionnaire design. We gratefully acknowledge Andrea Atencio, Laura Moreno, Jorge Pérez, Catalina Rey, Paul Rodríguez and Harold Villalba for their excellent research assistance; Luis Piñeros and Mauricio Castillo for the organization of the field work. For comments on previous drafts we thank two anonymous referees, Grant Miller, the participants on the IADB "Teenage Pregnancy" Workshop in Washington, the 
8th PEP General Meeting in Dakar, the NIP-LACEA meetings in Cali and Medellín, the LACEA 2010 conference in Medellin, the participants of the weekly seminars at the economic departments of Universidad de los Andes and Universidad del Rosario. We thank the help and support of the Health and Education Secretaries of Bogotá and the comments and information provided by Ana Gómez from DNP and Hernando Sánchez from Acción Social. The paper was finished while Darío Maldonado was a teacher at Universidad del Rosario; this author is grateful to Universidad del Rosario for their support and hospitality.

Funding: This paper is part of the project "Evaluating policies to reduce teenage childbearing in Bogotá, Colombia: the effect of policies reducing costs of education faced by households" (PIERI 11887) funded by PEP-BID-GRADE Teenage Childbearing Initiative in Latin America and the Caribbean and by FIUR from Universidad del Rosario.

\section{A Appendix}

Table 1: Differences between the two CCT programs.

\begin{tabular}{|c|c|c|}
\hline & Familias en Acción (FA) & Subsidio Educativo (SE) \\
\hline $\begin{array}{l}\text { Starting year } \\
\text { in Bogotá }\end{array}$ & 2009 & $\begin{array}{l}\text { First wave: } 2006 \\
\text { Second wave: } 2009 \text { with a completely } \\
\text { new cohort }\end{array}$ \\
\hline \multirow[t]{2}{*}{ Conditionality } & $\begin{array}{l}\text { Minimum day attendance: if the } \\
\text { minimum is not satisfied the } \\
\text { adolescent stops receiving the } \\
\text { subsidy in the current year but she } \\
\text { can recover it for the following year } \\
\text { after re-enrolling. }\end{array}$ & $\begin{array}{l}\text { Minimum day attendance: if the } \\
\text { minimum is not satisfied, the } \\
\text { adolescent permanently loses the aid. }\end{array}$ \\
\hline & & $\begin{array}{l}\text { Academic Achievement: renewal } \\
\text { depends on promotion to the } \\
\text { following grade }\end{array}$ \\
\hline $\begin{array}{l}\text { Target } \\
\text { population }\end{array}$ & Poor children at SISBEN level 1 & Poor children at SISBEN level 2 \\
\hline Eligibility & $\begin{array}{l}\text { Families with children enrolled in high } \\
\text { school (grades } 6 \text { to 11) }\end{array}$ & $\begin{array}{l}\text { Students enrolled in high school } \\
\text { (grades } 6 \text { to } 11 \text { ) }\end{array}$ \\
\hline
\end{tabular}


Table 1: (continued)

\begin{tabular}{|c|c|c|c|c|c|c|}
\hline & \multicolumn{3}{|c|}{ Familias en Acción (FA) } & \multicolumn{3}{|c|}{ Subsidio Educativo (SE) } \\
\hline Payments & \multicolumn{3}{|c|}{$\begin{array}{l}\$ 35,000 \text { Colombian pesos per month } \\
\text { for students enrolled in grades } 9 \text { th } \\
\text { and } 10 \text { th } \\
\$ 40,000 \text { Colombian pesos per month } \\
\text { at grade } 11 \text { th } \\
\text { Lump-sum of } \$ 430,000 \text { after } \\
\text { completing high school }\end{array}$} & \multicolumn{3}{|c|}{$\begin{array}{l}\$ 35,000 \text { Colombian pesos per month } \\
\text { for students in } 9 \text { th to } 11 \text { th grades. }\end{array}$} \\
\hline Duration & \multicolumn{3}{|c|}{$\begin{array}{l}\text { Six years of high school until the } \\
\text { student is } 18 \text { years }\end{array}$} & \multicolumn{3}{|c|}{$\begin{array}{l}\text { Two years during high school until the } \\
\text { student is } 18 \text { years }\end{array}$} \\
\hline \multicolumn{7}{|c|}{$\begin{array}{l}\text { This table does not offer a full description of the two programs; it concentrates in the } \\
\text { characteristics of the program that are relevant for our empirical exercises. We are leaving } \\
\text { aside all characteristics of the transfer related to children or students who are not in grades } \\
\text { 9th to 11th. }\end{array}$} \\
\hline \multicolumn{7}{|c|}{ Table 2: Treatments frequency. } \\
\hline & & \multirow[t]{2}{*}{ Total } & \multicolumn{2}{|c|}{$\begin{array}{r}\text { Familias en Acción } \\
\text { (FA) }\end{array}$} & \multicolumn{2}{|c|}{$\begin{array}{r}\text { Subsidio Educativo } \\
\text { (SE) }\end{array}$} \\
\hline & & & $\begin{array}{l}\text { Control } \\
\text { Schools }\end{array}$ & $\begin{array}{l}\text { Treated } \\
\text { Schools }\end{array}$ & $\begin{array}{l}\text { Control } \\
\text { Schools }\end{array}$ & $\begin{array}{l}\text { Treated } \\
\text { Schools }\end{array}$ \\
\hline \multirow{2}{*}{$\begin{array}{l}\text { Panel A: } \\
\text { Percent }\end{array}$} & Old Cohort & $53.35 \%$ & $37.14 \%$ & $16.20 \%$ & $30.32 \%$ & $23.03 \%$ \\
\hline & $\begin{array}{l}\text { Young Cohort } \\
\text { Total }\end{array}$ & $\begin{array}{r}46.65 \% \\
100.00 \%\end{array}$ & $\begin{array}{l}32.92 \% \\
70.06 \%\end{array}$ & $\begin{array}{l}13.73 \% \\
29.94 \%\end{array}$ & $\begin{array}{l}26.40 \% \\
56.72 \%\end{array}$ & $\begin{array}{l}20.26 \% \\
43.28 \%\end{array}$ \\
\hline \multirow{3}{*}{$\begin{array}{l}\text { Panel B: } \\
\text { Numbers }\end{array}$} & Old Cohort & 1,251 & 871 & 380 & 711 & 540 \\
\hline & Young Cohort & 1,094 & 772 & 322 & 619 & 475 \\
\hline & Total & 2,345 & 1,643 & 702 & 1,330 & 1,015 \\
\hline
\end{tabular}

See Appendix B for the meaning of each variable. 


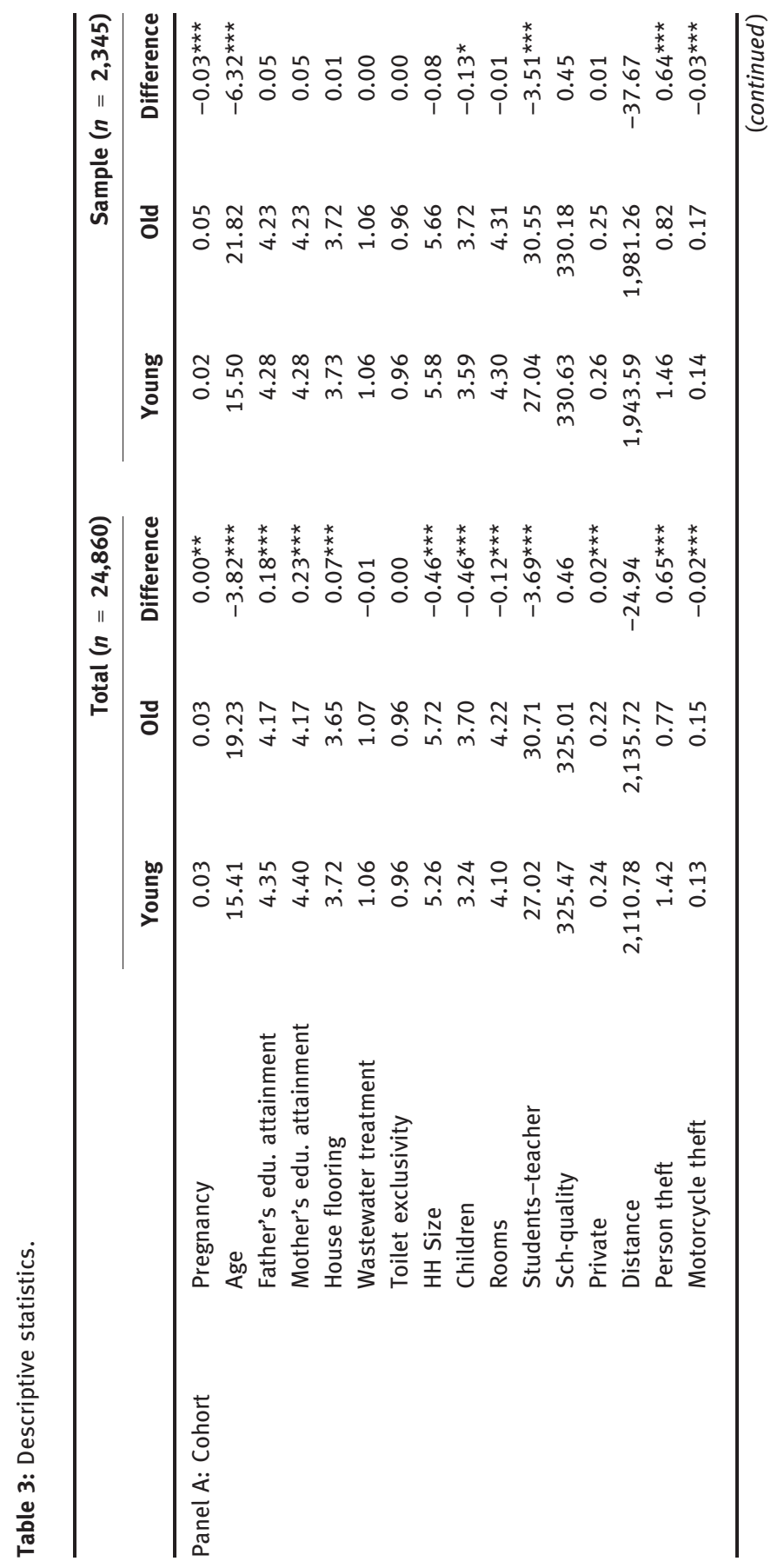




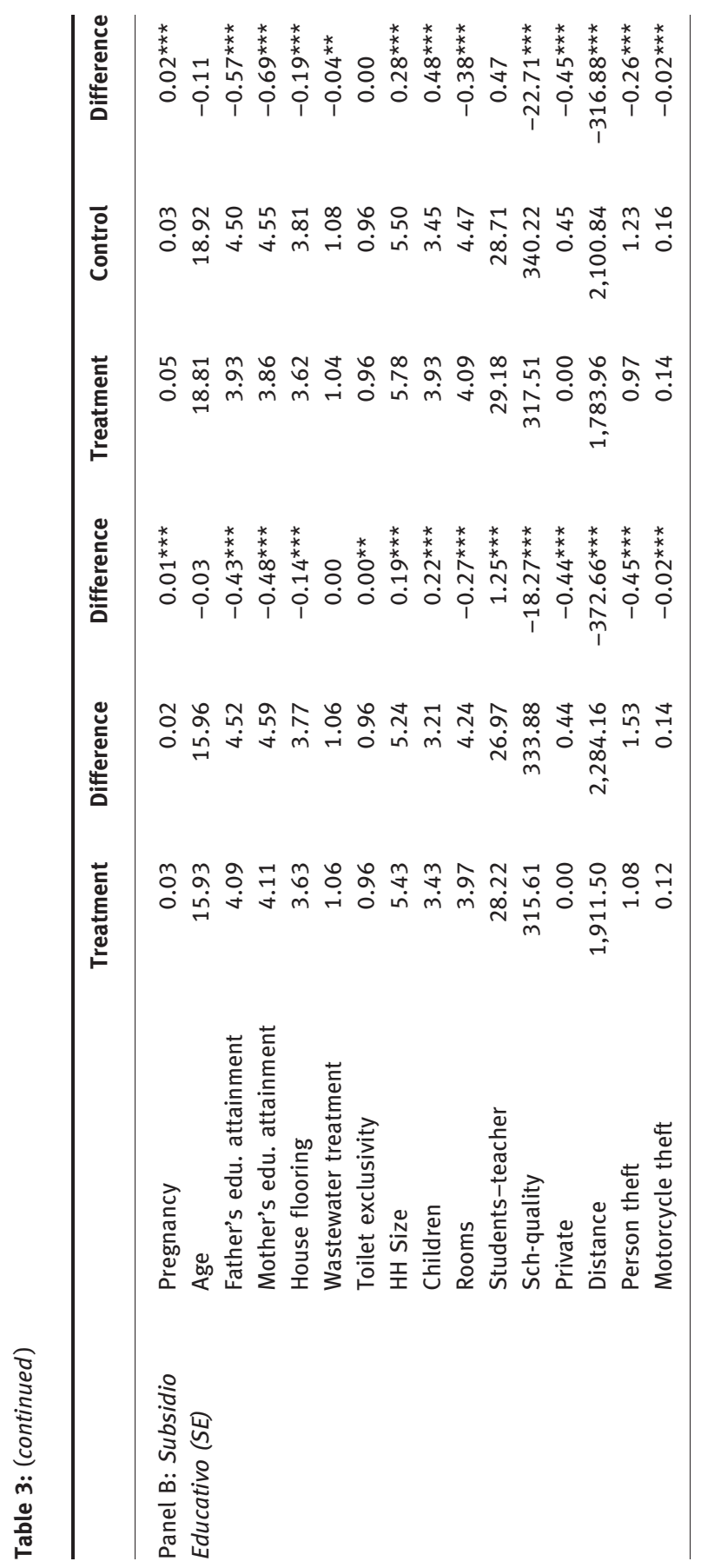




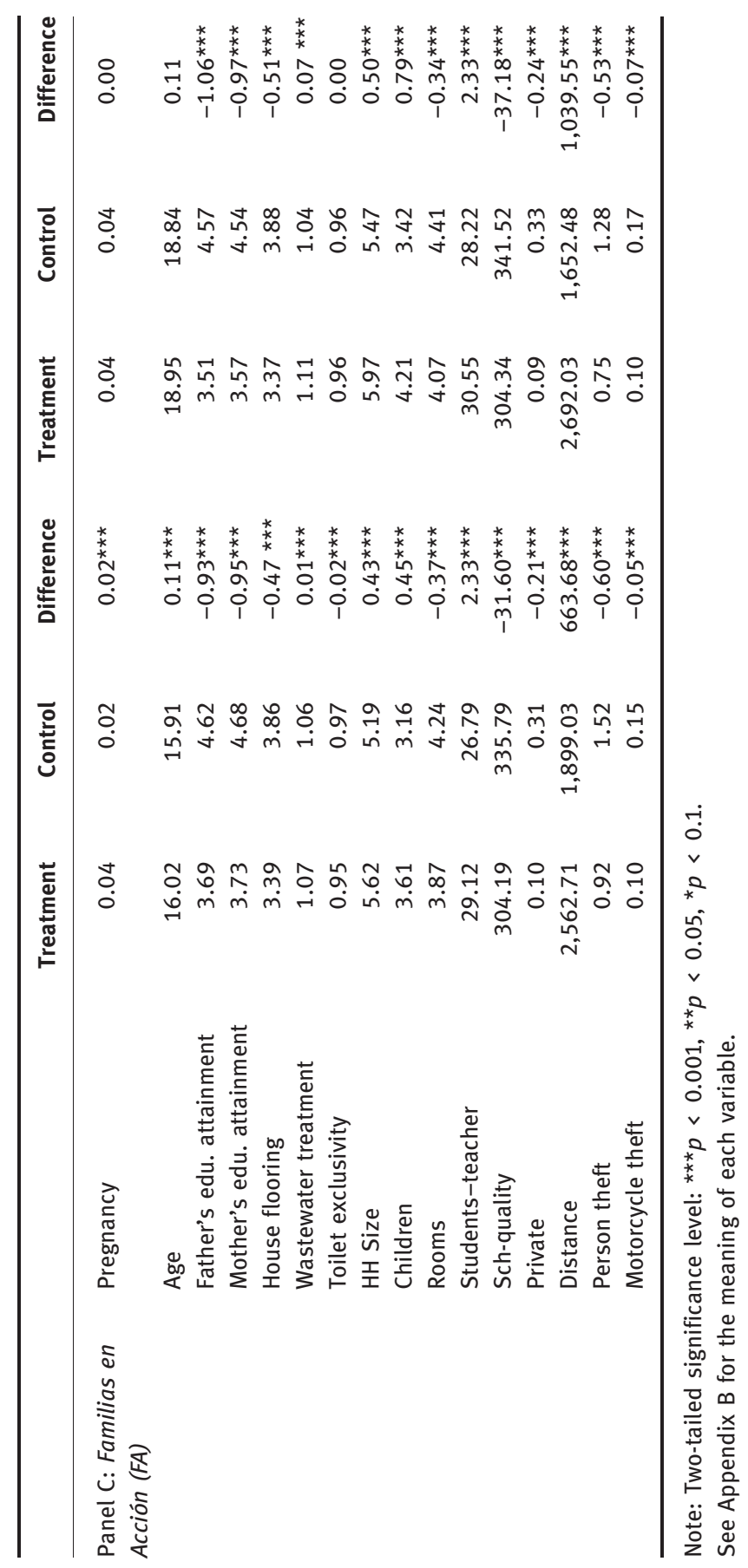


Table 4: Descriptive Diff-in-Diff in Teenage Pregnancy.

\begin{tabular}{|c|c|c|c|c|c|c|}
\hline & \multicolumn{3}{|c|}{ Familias en Acción (FA) } & \multicolumn{3}{|c|}{ Subsidio Educativo (SE) } \\
\hline & Control & Treated & Difference & Control & Treated & Difference \\
\hline \multirow[t]{2}{*}{ Old Cohort } & 0.053 & 0.050 & -0.003 & 0.035 & 0.074 & 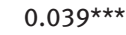 \\
\hline & $(0.223)$ & $(0.218)$ & $(0.013)$ & (0.184) & $(0.262)$ & $(0.012)$ \\
\hline \multirow[t]{2}{*}{ Young Cohort } & 0.018 & 0.037 & $0.019^{\star}$ & 0.023 & 0.025 & 0.002 \\
\hline & $(0.133)$ & (0.189) & $(0.010)$ & $(0.149)$ & $(0.157)$ & $(0.009)$ \\
\hline \multirow[t]{2}{*}{ Difference } & $-0.035^{\star \star \star}$ & -0.013 & $0.022^{\star \star}$ & -0.012 & $-0.049^{\star \star \star}$ & $-0.037^{\star}$ \\
\hline & $(0.009)$ & $(0.016)$ & $(0.010)$ & $(0.009)$ & $(0.013)$ & $(0.018)$ \\
\hline
\end{tabular}

See Appendix B for the meaning of each variable.

Table 5: Female school drop out rates and FA and SE 2008-2010.

\begin{tabular}{|c|c|c|c|c|c|c|}
\hline & \multicolumn{3}{|r|}{ Diff-in-diff } & \multicolumn{3}{|r|}{ Panel } \\
\hline & 8th grade & 9th grade & 10th grade & 8th grade & 9th grade & 10th grade \\
\hline Time $\times F A$ & $\begin{array}{c}-0.0189 \\
(0.0123)\end{array}$ & $\begin{array}{c}-0.0251 \\
(0.0167)\end{array}$ & $\begin{array}{c}-0.00591 \\
(0.0152)\end{array}$ & $\begin{array}{c}-0.0189 \\
(0.0121)\end{array}$ & $\begin{array}{c}-0.0251 \\
(0.0174)\end{array}$ & $\begin{array}{c}-0.00591 \\
(0.0161)\end{array}$ \\
\hline Time $\times S E$ & $\begin{array}{c}0.00489 \\
(0.0121)\end{array}$ & $\begin{array}{l}0.000873 \\
(0.0141)\end{array}$ & $\begin{array}{c}0.0152 \\
(0.0131)\end{array}$ & $\begin{array}{c}0.00489 \\
(0.0116)\end{array}$ & $\begin{array}{l}0.000873 \\
(0.0143)\end{array}$ & $\begin{array}{c}0.0152 \\
(0.0130)\end{array}$ \\
\hline Time $\times F A \times S E$ & $\begin{array}{l}-0.000645 \\
(0.0176)\end{array}$ & $\begin{array}{c}0.0121 \\
(0.0240)\end{array}$ & $\begin{array}{c}0.00456 \\
(0.0198)\end{array}$ & $\begin{array}{c}-0.000645 \\
(0.0178)\end{array}$ & $\begin{array}{c}0.0121 \\
(0.0252)\end{array}$ & $\begin{array}{c}0.00456 \\
(0.0205)\end{array}$ \\
\hline School FE & $v$ & $\checkmark$ & $\checkmark$ & $\checkmark$ & $\checkmark$ & $\checkmark$ \\
\hline Year FE & $v$ & $\checkmark$ & $\checkmark$ & $\checkmark$ & $\checkmark$ & $\checkmark$ \\
\hline Number of schools & & & & 194 & 194 & 194 \\
\hline Observations & 1,122 & 1,124 & 1,100 & 1,122 & 1,124 & 1,100 \\
\hline
\end{tabular}

Robust standard errors in parentheses.

Significance: ${ }^{* \star *} \underline{p}<0.01,{ }^{* *} p<0.05,{ }^{*} p<0.1$. 
Table 6: Main results.

\begin{tabular}{|c|c|c|c|c|c|c|}
\hline & $\begin{array}{r}\text { (1) } \\
\text { OLS }\end{array}$ & $\begin{array}{r}(2) \\
\text { OLS }\end{array}$ & $\begin{array}{r}(3) \\
\text { OLS }\end{array}$ & $\begin{array}{r}(4) \\
\text { OLS }\end{array}$ & $\begin{array}{r}(5) \\
\text { Probit }\end{array}$ & $\begin{array}{r}\text { (6) } \\
\text { Probit }\end{array}$ \\
\hline Cohort $\times F A$ & $\begin{array}{c}0.0130 \\
(0.0180)\end{array}$ & $\begin{array}{c}0.0130 \\
(0.0209)\end{array}$ & $\begin{array}{c}0.0137 \\
(0.0180)\end{array}$ & $\begin{array}{c}0.0174 \\
(0.0195)\end{array}$ & $\begin{array}{c}0.0187 \\
(0.0234)\end{array}$ & $\begin{array}{c}0.0226 \\
(0.0209)\end{array}$ \\
\hline Cohort $\times S E$ & $\begin{array}{c}-0.0479 * * \\
(0.0193)\end{array}$ & $\begin{array}{c}-0.0435^{\star \star} \\
(0.0198)\end{array}$ & $\begin{array}{l}-0.0489^{\star \star} \\
(0.0189)\end{array}$ & $\begin{array}{c}-0.0457^{\star *} \\
(0.0188)\end{array}$ & $\begin{array}{r}-0.0238^{\star *} \\
(0.00962)\end{array}$ & $\begin{array}{r}-0.0172^{\star *} \\
(0.00694)\end{array}$ \\
\hline School FE & V & $\checkmark$ & & & & \\
\hline Age & V & $\checkmark$ & $\checkmark$ & $\checkmark$ & $\checkmark$ & V \\
\hline Family controls & & $\checkmark$ & & $\checkmark$ & & $\checkmark$ \\
\hline School controls & & $\sqrt{ }$ & & $\checkmark$ & & $\checkmark$ \\
\hline Localidad & & $\checkmark$ & & $\checkmark$ & & $\checkmark$ \\
\hline Observations & 2,345 & 2,345 & 2,345 & 2,345 & 2,345 & 2,289 \\
\hline
\end{tabular}

Note: Standard errors clustered by localidad. Significance level: ${ }^{\star \star *} p<0.001,{ }^{\star \star} p<0.05,{ }^{\star} p<0.1$. See Appendix B for the meaning of each variable.

Table 7: Heterogeneous Effects 1.

\begin{tabular}{|c|c|c|c|c|}
\hline Panel A: By Grade & (1) & (2) & (3) & (4) \\
\hline Cohort $\times F A$ & $\begin{array}{l}0.0130 \\
(0.0209)\end{array}$ & $\begin{array}{c}0.0135 \\
(0.0209)\end{array}$ & & \\
\hline Cohort $\times F A$ 9th grade & & & $\begin{array}{l}0.00983 \\
(0.0339)\end{array}$ & $\begin{array}{c}0.00914 \\
(0.0328)\end{array}$ \\
\hline Cohort $\times F A$ 10th grade & & & $\begin{array}{l}0.0474^{\star \star} \\
(0.0189)\end{array}$ & $\begin{array}{l}0.0512^{\star \star} \\
(0.0195)\end{array}$ \\
\hline Cohort $\times F A$ 11th grade & & & $\begin{array}{c}-0.00878 \\
(0.0219)\end{array}$ & $\begin{array}{c}-0.00894 \\
(0.0227)\end{array}$ \\
\hline Cohort $\times S E$ & $\begin{array}{l}-0.0435^{\star \star} \\
(0.0198)\end{array}$ & & $\begin{array}{l}-0.0428^{\star *} \\
(0.0199)\end{array}$ & \\
\hline Cohort $\times S E$ 9th grade & & $\begin{array}{c}-0.0215 \\
(0.0173)\end{array}$ & & $\begin{array}{c}-0.0207 \\
(0.0168)\end{array}$ \\
\hline Cohort $\times S E$ 10th grade & & $\begin{array}{c}-0.0599^{\star \star} \\
(0.0209)\end{array}$ & & $\begin{array}{l}-0.0634^{\star \star \star} \\
(0.0210)\end{array}$ \\
\hline Cohort $\times S E$ 11th grade & & $\begin{array}{c}-0.0395 \\
(0.0295)\end{array}$ & & $\begin{array}{r}-0.0356 \\
(0.0299)\end{array}$ \\
\hline Observations & 2,345 & 2,345 & 2,345 & 2,345 \\
\hline
\end{tabular}


Table 7: (continued)

\begin{tabular}{|c|c|c|c|c|}
\hline Panel B: By Age & (1) & (2) & (3) & (4) \\
\hline Cohort $\times F A$ & $\begin{array}{l}0.0130 \\
(0.0209)\end{array}$ & $\begin{array}{c}0.0119 \\
(0.0212)\end{array}$ & & \\
\hline Cohort $\times$ FA age 14 & & & $\begin{array}{c}-0.0132 \\
(0.0223)\end{array}$ & $\begin{array}{c}-0.0138 \\
(0.0229)\end{array}$ \\
\hline Cohort $\times$ FA age 15 & & & $\begin{array}{c}0.0346 \\
(0.0203)\end{array}$ & $\begin{array}{c}0.0332 \\
(0.0195)\end{array}$ \\
\hline Cohort $\times$ FA age 16 & & & $\begin{array}{l}0.0493^{\star *} \\
(0.0224)\end{array}$ & $\begin{array}{l}0.0468^{\star \star} \\
(0.0202)\end{array}$ \\
\hline Cohort $\times$ FA age 17 & & & $\begin{array}{c}-0.00762 \\
(0.0526)\end{array}$ & $\begin{array}{c}0.00364 \\
(0.0558)\end{array}$ \\
\hline Cohort $\times$ FA age 18 & & & $\begin{array}{c}-0.142^{\star} \\
(0.0753)\end{array}$ & $\begin{array}{l}-0.149^{\star} \\
(0.0767)\end{array}$ \\
\hline Cohort $\times S E$ & $\begin{array}{l}-0.0435^{\star *} \\
(0.0198)\end{array}$ & & $\begin{array}{l}-0.0427^{\star \star} \\
(0.0200)\end{array}$ & \\
\hline Cohort $\times$ SE age 14 & & $\begin{array}{c}-0.0427^{\star} \\
(0.0228)\end{array}$ & & $\begin{array}{r}-0.0389^{\star} \\
(0.0224)\end{array}$ \\
\hline Cohort $\times$ SE age 15 & & $\begin{array}{l}-0.0378^{\star \star} \\
(0.0167)\end{array}$ & & $\begin{array}{l}-0.0387^{\star *} \\
(0.0151)\end{array}$ \\
\hline Cohort $\times$ SE age 16 & & $\begin{array}{c}-0.0263 \\
(0.0299)\end{array}$ & & $\begin{array}{c}-0.0303 \\
(0.0302)\end{array}$ \\
\hline Cohort $\times$ SE age 17 & & $\begin{array}{r}-0.103^{\star *} \\
(0.0419)\end{array}$ & & $\begin{array}{r}-0.100 * * \\
(0.0446)\end{array}$ \\
\hline Cohort $\times$ SE age 18 & & $\begin{array}{l}0.00334 \\
(0.0898)\end{array}$ & & $\begin{array}{c}0.0201 \\
(0.0853)\end{array}$ \\
\hline Observations & 2,345 & 2,345 & 2,345 & 2,345 \\
\hline
\end{tabular}

Note: Standard errors are clustered by localidad; all regressions include cohort and school fixed effects.

Significance level: ${ }^{* \star *} p<0.001,{ }^{* \star} \underline{p}<0.05,{ }^{*} p<0.1$.

See Appendix B for the meaning of each variable. 
Table 8: Robustness Checks 1.

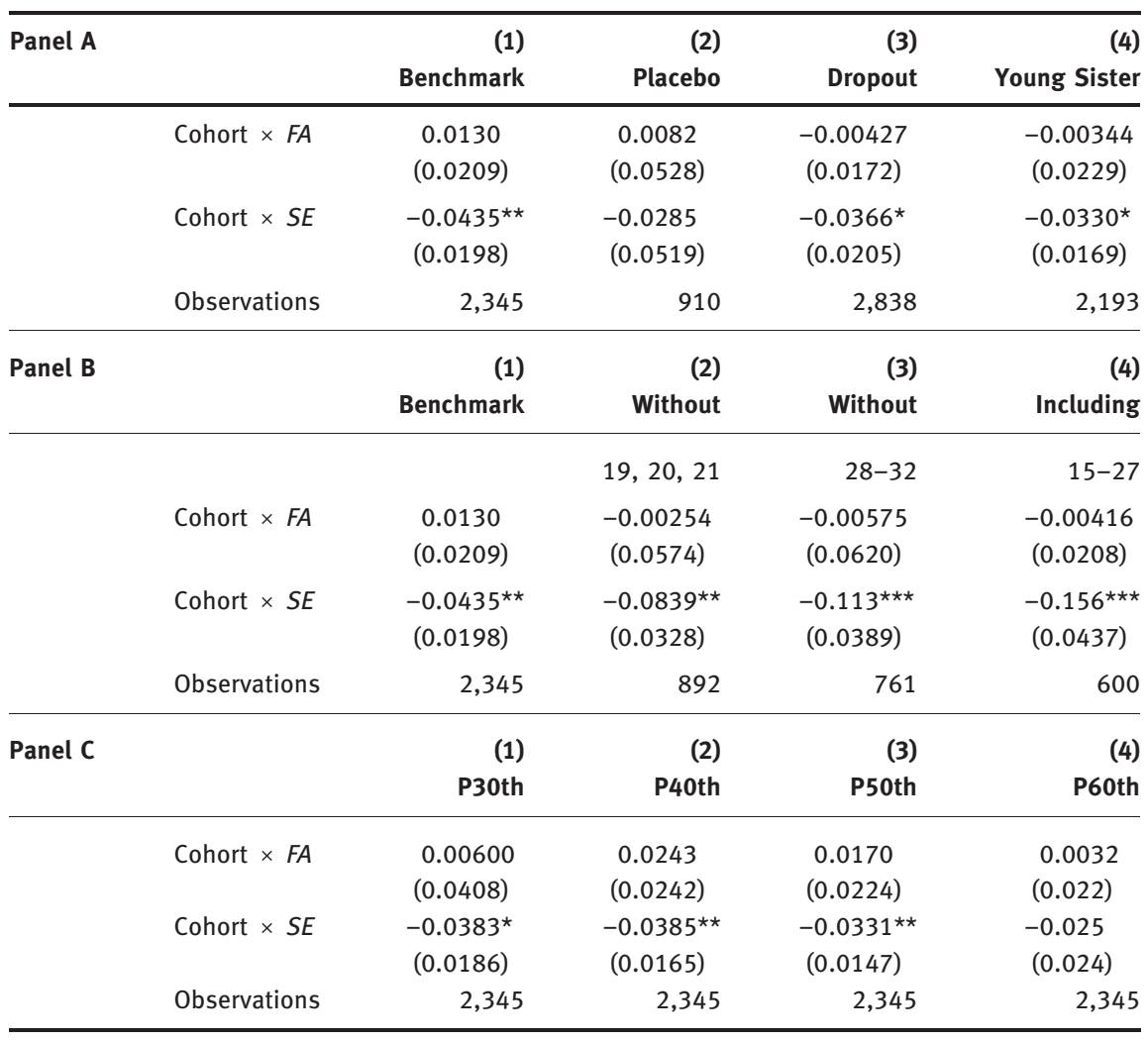

Note: In column 1 of each panel we report the results showed in column 2, Table 6 as a benchmark. In column 2, Panel A, we report results of the placebo treatment. We split the sample of the old cohort in two: younger sisters (19-22 years old) and older sisters (23-32 years old). In column 3, Panel A, we include in the regression sisters that dropped out from school. In column 4, Panel A, we run the benchmark but we only keep the younger sister and the corresponding interviewed girl. In Panel $B$ we report a sequence of regression in which we test whether our results are robust to the definition of cohort. In column 2, Panel B, we exclude the younger sisters from the old cohort. In column 3, Panel B, we exclude the older sisters from the old cohort. In column 4, Panel B, we exclude older sisters and younger interviewed girls with the aim to have girls of similar age in both cohorts. In Panel C, we report results obtained when we change the threshold that defines the treatment variable. We use different percentiles ranging from 30 th percentile to 50 th percentile.

Standard errors are clustered by localidad; all regressions include cohort and school fixed effects.

Significance level: ${ }^{\star \star *} p<0.001,{ }^{\star *} p<0.05,{ }^{*} p<0.1$.

See Appendix $B$ for the meaning of each variable. 
Table 9: Robustness checks 2 - Matching (Exercises in columns 1 and 2 of Table 6 using a matched sample).

\begin{tabular}{lrr}
\hline & (1) & (2) \\
& OLS & OLS \\
\hline Cohort $\times F A$ & 0.0113 & 0.00665 \\
& $(0.0194)$ & $(0.0243)$ \\
Cohort $\times S E$ & $-0.0420^{\star}$ & $-0.0445^{\star}$ \\
School FE & $(0.0230)$ & $(0.0231)$ \\
Age & $\sqrt{ }$ & $\mathrm{V}$ \\
Family controls & $\mathrm{V}$ & $\mathrm{V}$ \\
School controls & & $\mathrm{V}$ \\
Localidad & & $\mathrm{V}$ \\
Observations & 2,226 & $\mathrm{~V}$ \\
\hline
\end{tabular}

Note: Standard errors clustered by localidad. Significance level: ${ }^{\star \star \star} p<0.001$, ${ }^{* *} p<0.05,{ }^{*} p<0.1$.

See Appendix $B$ for the meaning of each variable.

Table 10: Matching (first step) - Covariates Test across treatment groups.

\begin{tabular}{|c|c|c|c|c|c|c|c|}
\hline \multirow[t]{2}{*}{ Variable } & \multirow[t]{2}{*}{ Sample } & \multicolumn{2}{|r|}{ Mean } & \multicolumn{2}{|c|}{ \%Reduct } & \multicolumn{2}{|r|}{ t-test } \\
\hline & & SE & FA & $\%$ bias & $\mid$ bias $\mid$ & $\mathbf{t}$ & $p>|t|$ \\
\hline \multirow[t]{2}{*}{ Age } & Unmatched & 15.417 & 15.646 & -20.6 & 90.4 & -2.57 & 0.010 \\
\hline & Matched & 15.451 & 15.429 & 2.0 & & 0.26 & 0.795 \\
\hline \multirow[t]{2}{*}{ Father's educ. attain. } & Unmatched & 4.1741 & 3.5169 & 42.2 & 62.9 & 5.28 & 0.000 \\
\hline & Matched & 4.0498 & 3.806 & 15.7 & & 1.76 & 0.079 \\
\hline \multirow[t]{2}{*}{ Mother's educ. attain. } & Unmatched & 4.0773 & 3.5755 & 34.0 & 64.2 & 4.25 & 0.000 \\
\hline & Matched & 3.9793 & 3.7997 & 12.2 & & 1.53 & 0.126 \\
\hline \multirow[t]{2}{*}{ House flooring } & Unmatched & 3.7627 & 3.3602 & 44.9 & 95.1 & 5.58 & 0.000 \\
\hline & Matched & 3.7558 & 3.7363 & 2.2 & & 0.31 & 0.759 \\
\hline \multirow[t]{2}{*}{ Wastewater treatment } & Unmatched & 1.0232 & 1.1118 & -23.7 & 91.7 & -2.93 & 0.004 \\
\hline & Matched & 1.022 & 1.0147 & 2.0 & & 0.58 & 0.562 \\
\hline \multirow[t]{2}{*}{ Toilet exclusivity } & Unmatched & .95613 & .96871 & -6.7 & 94.9 & -0.83 & 0.406 \\
\hline & Matched & .95513 & .95577 & -0.3 & & -0.04 & 0.971 \\
\hline \multirow[t]{2}{*}{ Rooms } & Unmatched & 4.1457 & 4.0528 & 6.7 & 72.4 & 0.83 & 0.406 \\
\hline & Matched & 4.0842 & 4.1099 & -1.8 & & -0.23 & 0.822 \\
\hline \multirow[t]{2}{*}{$\mathrm{HH}$ size } & Unmatched & 5.6854 & 5.9596 & -12.8 & 94.7 & -1.59 & 0.112 \\
\hline & Matched & 5.7436 & 5.7582 & -0.7 & & -0.08 & 0.934 \\
\hline
\end{tabular}


Table 10: (continued)

\begin{tabular}{|c|c|c|c|c|c|c|c|}
\hline \multirow[t]{2}{*}{ Variable } & \multirow[t]{2}{*}{ Sample } & \multicolumn{2}{|r|}{ Mean } & \multicolumn{2}{|c|}{ \%Reduct } & \multicolumn{2}{|r|}{ t-test } \\
\hline & & SE & FA & $\%$ bias & bias & $\mathbf{t}$ & $p>|t|$ \\
\hline \multirow[t]{2}{*}{ Children } & Unmatched & 3.6689 & 4.1677 & -25.7 & 91.9 & -3.22 & 0.001 \\
\hline & Matched & 3.7509 & 3.7912 & -2.1 & & -0.25 & 0.800 \\
\hline \multirow[t]{2}{*}{ Students-teacher } & Unmatched & 27.931 & 28.58 & -16.0 & 45.5 & -2.00 & 0.046 \\
\hline & Matched & 27.776 & 28.13 & -8.7 & & -1.00 & 0.318 \\
\hline \multirow[t]{2}{*}{ Sch-quality } & Unmatched & 325.58 & 304.87 & 99.9 & 77.9 & 12.49 & 0.000 \\
\hline & Matched & 319.81 & 315.22 & 22.1 & & 3.62 & 0.000 \\
\hline
\end{tabular}

See Appendix B for the meaning of each variable.

Table 11: Matching (second step) - covariates test across matched treatment and control group.

\begin{tabular}{|c|c|c|c|c|c|c|c|}
\hline \multirow[t]{2}{*}{ Variable } & \multirow[t]{2}{*}{ Sample } & \multicolumn{2}{|r|}{ Mean } & \multicolumn{2}{|c|}{ \%Reduct } & \multicolumn{2}{|r|}{ t-test } \\
\hline & & Treated & Control & $\%$ bias & |bias & $\mathbf{t}$ & $p>|t|$ \\
\hline \multirow[t]{2}{*}{ Age } & Unmatched & 15.556 & 15.443 & 10.6 & 32.1 & 1.71 & 0.087 \\
\hline & Matched & 15.553 & 15.475 & 7.2 & & 1.25 & 0.210 \\
\hline \multirow[t]{2}{*}{ Father's educ. attain. } & Unmatched & 3.7614 & 4.8847 & -65.0 & 98.2 & -10.64 & 0.000 \\
\hline & Matched & 3.8164 & 3.7965 & 1.2 & & 0.22 & 0.822 \\
\hline \multirow[t]{2}{*}{ Mother's educ. attain. } & Unmatched & 3.7607 & 4.8872 & -70.2 & 97.2 & -11.49 & 0.000 \\
\hline & Matched & 3.8146 & 3.8456 & -1.9 & & -0.38 & 0.703 \\
\hline \multirow[t]{2}{*}{ House flooring } & Unmatched & 3.5417 & 3.9678 & -50.9 & 91.5 & -8.14 & 0.000 \\
\hline & Matched & 3.6006 & 3.6368 & -4.3 & & -0.73 & 0.465 \\
\hline \multirow[t]{2}{*}{ Wastewater treatment } & Unmatched & 1.0706 & 1.0532 & 4.9 & 19.3 & 0.79 & 0.429 \\
\hline & Matched & 1.0649 & 1.0509 & 4.0 & & 0.70 & 0.487 \\
\hline \multirow[t]{2}{*}{ Toilet exclusivity } & Unmatched & .96248 & .96363 & -0.6 & 94.1 & -0.10 & 0.921 \\
\hline & Matched & .96259 & .96266 & -0.0 & & -0.01 & 0.995 \\
\hline \multirow[t]{2}{*}{ Rooms } & Unmatched & 4.0672 & 4.5745 & -37.6 & 95.2 & -6.06 & 0.000 \\
\hline & Matched & 4.0807 & 4.0561 & 1.8 & & 0.30 & 0.762 \\
\hline \multirow[t]{2}{*}{ HH size } & Unmatched & 5.8605 & 5.2468 & 29.2 & 54.8 & 4.71 & 0.000 \\
\hline & Matched & 5.7614 & 5.4842 & 13.2 & & 2.37 & 0.018 \\
\hline \multirow[t]{2}{*}{ Children } & Unmatched & 3.9765 & 3.1511 & 50.5 & 63.0 & 7.97 & 0.000 \\
\hline & Matched & 3.7614 & 3.4561 & 18.7 & & 3.91 & 0.000 \\
\hline \multirow[t]{2}{*}{ Students-teacher } & Unmatched & 28.211 & 25.415 & 56.2 & 95.2 & 9.28 & 0.000 \\
\hline & Matched & 28.122 & 27.988 & 2.7 & & 0.60 & 0.546 \\
\hline \multirow[t]{2}{*}{ Private } & Unmatched & .05042 & .54255 & -127.8 & 99.3 & -21.58 & 0.000 \\
\hline & Matched & .05263 & .05614 & -0.9 & & -0.26 & 0.794 \\
\hline \multirow[t]{2}{*}{ Person theft } & Unmatched & 1.2059 & 1.7491 & -43.2 & 98.0 & -7.15 & 0.000 \\
\hline & Matched & 1.2239 & 1.2132 & 0.8 & & 0.19 & 0.852 \\
\hline
\end{tabular}

See Appendix B for the meaning of each variable. 


\section{B Variable Glossary}

\begin{tabular}{|c|c|}
\hline Variable & Definition \\
\hline Children & Number of mother's children \\
\hline Cohort & $\begin{array}{l}\text { Identifies cohort, 1: Interviewed girls, 0: Sisters of interviewed } \\
\text { girls }\end{array}$ \\
\hline Distance & Distance of school to nearest Transmilenio station \\
\hline FA & Holds the CCT FA \\
\hline$S E$ & Holds the CCT SE \\
\hline HH Size & Household size including the student \\
\hline Motorcycle theft & $\begin{array}{l}\text { Motorcycle theft rate (one per } 100 \text { thousand inhabitants) by } \\
\text { localidad }\end{array}$ \\
\hline Person theft & $\begin{array}{l}\text { Thefts to persons rate (one per } 100 \text { thousand inhabitants) by } \\
\text { localidad }\end{array}$ \\
\hline Private & 1 if she studies in a private school \\
\hline Rooms & $\begin{array}{l}\text { Number of rooms in the student's house excluding kitchen, bath- } \\
\text { rooms or garages }\end{array}$ \\
\hline Sch-quality & Average math results of students in 5 year of primary school 2009 \\
\hline Father's edu. attainment & $\begin{array}{l}310 \mathrm{~cm} 1=\text { No Education, } 2=\text { Incomplete Primary, } 3=\text { Complete } \\
\text { Primary, } 4=\text { I. Secondary, } 5=\text { C. Secondary, } 6=\mathrm{I} . \text { undergrad., } \\
7=\text { C. undergrad., } 8=\text { Graduate }\end{array}$ \\
\hline Mother's edu. attainment & $\begin{array}{l}310 \mathrm{~cm} 1=\text { No Education, } 2=\text { Incomplete Primary, } 3=\text { Complete } \\
\text { Primary, } 4=\mathrm{I} . \text { Secondary, } 5=\text { C. Secondary, } 6=\mathrm{I} . \text { undergrad., } \\
7=\text { C. undergrad., } 8=\text { Graduate }\end{array}$ \\
\hline House flooring & $\begin{array}{l}310 \mathrm{~cm} 1=\text { Sand or dirt, } 2=\text { Cement or pebble, } 3=\text { Unpolished } \\
\text { wood, } 4=\text { Tiles, bricks or vinyl, } 5=\text { Polished wood, carpet, rug or } \\
\text { marble }\end{array}$ \\
\hline Wastewater treatment & $\begin{array}{l}210 \mathrm{~cm} 1=\text { Sewerage, } 2=\text { Septic tank, } 3=\text { Unconnected toilet, } \\
4=\text { Latrine, } 5=\text { None }\end{array}$ \\
\hline Toilet exclusivity & 0 if shared with other households, 1 if exclusive \\
\hline Students-teacher & $\begin{array}{l}\text { Students-teacher relationship ( } 2004 \text { for sisters, } 2008 \\
\text { for interviewed) }\end{array}$ \\
\hline
\end{tabular}

\section{References}

Alzua, M. L., C. Rodríguez, and E. Villa. 2015. Can Compulsory Education Reforms Reduce Teenage Pregnancy? Evidence from Latina America and the Caribbean. Mimeo.

Angrist, J., and W. N. Evans. 1996. Schooling and Labor Market Consequences of the 1970 State Abortion Reforms. NBER Working Papers 5406, National Bureau of Economic Research, Inc.

Ashcraft, A., I. Fernández-Val, and K. Lang. 2013. "The Consequences of Teenage Childbearing: Consistent Estimates When Abortion Makes Miscarriage Non-Radom.” The Economic Journal 123:875-905.

Attanasio, O., E. Fitzsimos, A. Gómez, M. I. Gutiérrez, C. Meghir, and A. Mesnard. 2010. “Children's Schooling and Work in the Presence of a Conditional Cash Transfer Program in Rural Colombia." Economic Development and Cultural Change 58 (2):181-210. 
Baez, J. E., and A. Camacho. 2011. Assessing the Long-term Effects of Conditional Cash Transfers on Human Capital: Evidence from Colombia. IZA Discussion Papers 5751, Institute for the Study of Labor (IZA).

Baird, S., E. Chirwa, C. McIntosh, and B. Özler. 2010. "The Short-Term Impacts of a Schooling Conditional Cash Transfer Program on the Sexual Behavior of Young Women." Health Economics 19 (S1):55-68.

Baird, S., C. McIntosh, and B. Özler. 2011. "Cash or Condition? Evidence From a Cash Transfer Experiment.” The Quarterly Journal of Economics 126 (4):1709-53.

Barrera, F., M. Bertrand, L. Linden, and F. Perez. 2011. "Improving the Design of Conditional Transfer Programs: Evidence From a Randomized Education Experiment in Colombia." American Economic Journal: Applied Economics 3 (2):167-95.

Behrman, J., S. Parker, and P. Todd. 2009. "Medium-Term Impacts of the Oportunidades Conditional Cash Transfer Program on Rural Youth in Mexico." In Poverty, Inequality and Policy in Latin America, edited by Stephan Klasen and Felicitas Nowak-Lehmman. Cambridge, MA: MIT Press.

Bethelon, M., and D. Kruger. 2011. "Risky Behavior Among Youth: Incapacitation Effects of School on Adolescent Motherhood and Crime in Chile." Journal of Public Economics 95 (1-2):41-53.

Black, S. E., P. J. Devereux, and K. G. Salvanes. 2008. "Staying in the Classroom and Out Of the Maternity Ward? The Effect of Compulsory Schooling Laws in Teenage Births." The Economic Journal 118 (530):1025-54.

Brien, M. J., G. E. Loya, and J. V. Pepper. 2002. "Teenage Childbearing and Cognitive Development.” Journal of Population Economics 15:391-416.

Camacho, A., and E. Conover. 2011. "Manipulation of Social Program Eligibility." American Economic Journal: Economic Policy 3 (2):41-65.

Chevalier, A., and T. K. Viitanen. 2003. "The Long-Run Labour Market Consequences of Teenage Motherhood in Britain." Journal of Population Economics 16:323-43.

Dahl, G. B. 2010. “Early Teen Marriage and Future Poverty.” Demography 47 (3):689-718.

de Janvry, A., F. Finan, E. Sadoulet, and R. Vakis. 2006. "Can Conditional Cash Transfer Programs Serve as Safety Nets in Keeping Children at School and From Working When Exposed to Shocks?" Journal of Development Economics 79 (2):349-73.

Duflo, E. 2001. "Schooling and Labor Market Consequences of School Construction in Indonesia: Evidence From an Unusual Policy Experiment." The American Economic Review 91 (4):795-813.

Duflo, E., P. Dupas, M. Kremer, and S. Sinei 2006. Education and HIV/AIDS Prevention. Background paper to the 2007 Development Report, The World Bank, Working paper 4024.

Field, E., and A. Ambrus. 2008. "Early Marriage, Age of Menarche, and Female Schooling Attainment in Bangladesh." Journal of Political Economy 116 (5):881-930.

Fletcher, J. M. 2012. "The Effects of Teenage Childbearing on the Short and Long-Term Health Behaviors of Mothers." Journal of Population Economics 25:201-18.

Fletcher, J. M., and B. Wolfe. 2009. "Education and Labor Market Consequences of Teenage Childbearing." The Journal of Human Resources 44 (2):303-25.

Flórez, C. E., and J. Núñez. 2001. Teenage Childbearing in Latin American Countries. Interamerican Development Bank, Research Network working paper R-434.

Flórez, C. E., and V. E. Soto. 2008. El estado de la salud sexual y reproductiva en América Latina y el Caribe: Una visión global. IDB, RES Working Papers, 4572. 
Geronimus, A. T. 1993. "Maternal Youth or Family Background? on the Health Disadvantages of Infants with Teenage Mothers.” American Journal of Epidemiology 137 (2):213-25.

Geronimus, A. T., and S. Korenman. 1992. "The Socioeconomic Consequences of Teen Childbearing Reconsidered.” The Quarterly Journal of Economics 107 (4):1187-121.

Hoffman, S. D., E. Michael Foster, and F. F. Furstenberg. 1993. "Reevaluating the Costs of Teenage Childbearing." Demography 30 (1):1-13.

Holmlund, H. 2005. "Estimating Long Term Consequences of Teenage Childbearing: An Examination of the Siblings Approach." The Journal of Human Resources 30 (1):716-43.

Hotz, V. J., S. W. McElroy, and S. G. Sanders. 2005. "Teenage Childbearing and Its Life-Cycle Consequences: Exploiting a Natural Experiment.” Journal of Human Resources 40 (3): 683-715.

Hotz, J., V., C. H. Mullin, and S. G. Sanders. 1997. "Bounding Causal Effects Using Data From a Contaminated Natural Experiment: Analyzing the Effects of Teenage Childbearing." Review of Economic Studies 64 (4):576-603.

IEG (Independent Evaluation Group). 2011. Do Conditional Cash Transfers Lead to Medium-Term Impacts?: Evidence From a Female School Stipend Program in Pakistan. Washington, DC: World Bank.

Levine, D. I., and G. Painter. 2003. "The Costs of Teenage Out-of-Wedlock Childbearing: Analysis with a Within-School Propensity Score." Review of Economics and Statistics 85 (4):884-99.

Lundberg, S., and R. D. Plotnick. 1995. "Adolescent Premarital Childbearing: Do Economic Incentives Matter?" Journal of Labor Economics 13 (2):177-200.

Miller, G. 2010. "Contraception as Development? New Evidence From Family Planning in Colombia." The Economic Journal 120 (545):709-37.

Rosenbaum, P. R., and D. B. Rubin. 1985. "Constructing a Control Group Using Multivariate Matched Sampling Methods That Incorporate the Propensity Score." The American Statistician 39 (1):33-8.

Schultz, P.,T. 2004. "School Subsidies for the Poor: Evaluating the Mexican Progress Poverty Program.” Journal of Development Economics 74 (1):199-250.

Silles, M. A. 2011. "The Effect of Schooling on Teenage Childbearing: Evidence Using Changes in Compulsory Education Laws." Journal of Population Economics 24:761-77.

Urdinola, P., and C. Ospino. 2015. "Long-Term Consequences of Adolescent Fertility: The Colombian Case.” Demographic Research 33:Article 55.

Wolfe, B., K. Wilson, and R. Haveman. 2001. "The Role of Economic Incentives in Teenage Non-Marital Childbearing Choices.” Journal of Public Economics 81 (3):473-511. 